ANUARIO MUSICAL, N. ${ }^{\circ} 68$

enero-diciembre 2013, 263-292

ISSN: 0211-3538

\title{
ESTILO GALANTE Y SINFONÍAS DE F. J. HAYDN EN LA CAPILLA DE MÚSICA DE LA CATEDRAL DE SANTIAGO DE COMPOSTELA DURANTE EL MAGISTERIO DE MELCHOR LÓPEZ (1783-1822): LA RENOVACIÓN DEL REPERTORIO INSTRUMENTAL
}

\author{
GALANT STYLE AND SYMPHONIES BY F. J. HAYDN IN THE MUSIC \\ CHAPEL OF SANTIAGO DE COMPOSTELA CATHEDRAL RULED BY \\ THE MAESTRO DE CAPILLA MELCHOR LOPEZ (1783-1822): THE \\ RENEWAL OF THE INSTRUMENTAL REPERTOIRE
}

\section{F. Javier Garbayo Montabes}

Universidade de Santiago de Compostela

\begin{abstract}
Resumen:
De manera paralela al desarrollo del magisterio de capilla ejercido por Melchor López en la catedral de Santiago de Compostela (1783-1822), se produjo la renovación de su orquesta hasta alcanzar de un modo estable los patrones del tipo básico de orquesta sinfónica clásica surgido con fuerza en Europa central años antes. Este hecho influyó en la música del maestro, formado en Madrid y admirador de la música de F. J. Haydn, donde el acompañamiento orquestal preciosista a las voces solistas y al coro, se convirtió en protagonista de la misma, posibilitando además la renovación del repertorio instrumental que se interpretaba en las funciones litúrgicas (Misas, Vísperas) y en otros momentos paralelos a los litúrigicos como eran las siestas que se celebraban durante el octavario del Corpus. Dentro de esta renovación, tuvo especial importancia la recepción del estilo de Haydn, cuyas sinfonías llegaron a la catedral en la década de 1790 y son quizá el elemento más representativo de la renovación de dicho repertorio.
\end{abstract}

\section{Palabras clave:}

Siglo XVIII, Estilo Galante, Catedral Santiago de Compostela, Capillas Música, Melchor López, música instrumental, Haydn, sinfonía.

\footnotetext{
Abstract:

At the same time as Melchor López was carrying out his teaching duties within the music chapel of the cathedral of Santiago (1783-1822), the renovation of his orchestra was undertaken to the point of accomplishing a stable symphony orchestra of the classical sort which had long been firmly established in Central Europe. This greatly influenced the maestro's music, having studied in Madrid and admirer of F.J. Haydn's music, where the precise orchestral accompaniment for solo voices and for choirs became the central part of his works and made possible the renovation of the instrumental repertoire which was being used in the
} 
liturgy (Masses, Vespers) and on other occasions for paraliturgy functions such as the siestas celebrated during the octave of Corpus. Within this renovation, the reception of Haydn's influence was especially important: his symphonies arrived at the cathedral in the 1790 s and are perhaps the most representative element of this renovation which the aforementioned repertoire underwent.

\section{Keywords:} symphony.

$18^{\text {th }}$ century, Galant Style, Santiago de Compostela cathedral, Music Chapel, Melchor López, instrumental music, Haydn,

\section{INTRODUCCIÓN}

En la etapa comprendida entre los años 1783 y 1822, la catedral de Santiago de Compostela tuvo al frente del magisterio de su capilla a Melchor López Giménez, músico formado en el Real Colegio de cantorcicos de Madrid con José Lidón y destacado representante de la influencia del estilo de Haydn en las catedrales hispanas. Es este un período de cambios en nuestra música religiosa, situada en gran medida en la periferia de los grandes estilos internacionales. Un período donde hallamos una dualidad de lenguajes que lo convierten en espacio de discusión que en ocasiones hace difícil llegar a conclusiones conciliadoras al respecto, sobre todo en aspectos terminológicos para caracterizar su música. Por un lado hallamos activa a una gran generación de compositores formados en la tradición musical de un barroco peninsular, lleno de peculiaridades que obran en él de manera definitoria y diferenciadora respecto al resto de Europa y que siguen componiendo según cánones y maneras obsoletas en el tiempo comparativamente con lo que sucedía en el centro de Europa o en la misma Italia. Por otro, la apertura vivida por el reino de España con el final de la dinastía de los Austrias y la llegada a la corte de los Borbones, hicieron que, no sin retraso respecto a los países vecinos, nuestra sociedad, costumbres y cultura se modernizasen. Las aportaciones, teorías y logros que la Ilustración y del estilo Rococó, posteriormente del Racionalismo, Neoclasicismo y musicalmente del "nuevo estilo" musical que se venía fraguando desde antes de la muerte de Juan Sebastián Bach, también fueron conocidas y cultivadas en nuestro país. Las catedrales siguieron siendo entonces, con la corte, los principales focos de actividad musical aunque compartiendo su protagonismo cada vez en mayor medida con los salones de la nobleza ilustrada y de la burguesía y también con los teatros, en un fenómeno de creciente ascenso, difusión y gran suceso de la música fundamentalmente profana, común al resto de Europa.

Pese a ello, muchas dudas se plantean al investigador que se acerca al período respecto a la adopción de una terminología adecuada para la época que nos ocupa, un momento en el que en la música de las catedrales se verifica una cierta unidad de circunstancias y consecuencias que derivan en modos y maneras también comunes. La gran crisis vivida entonces por las capillas de música llevará a muchas de ellas a su total desaparición, marcando claramente un final de ciclo, a pesar de que tras el Concordato de 1852 y con su restauración parcial, la música religiosa española volvería a cobrar vida, no sin seguir mostrando esa arraigada ambivalencia de posiciones antes comentada, es decir, lenguaje del pasado versus lenguaje más novedoso. 
De dicha situación se hace eco Hilarión Eslava en su Breve Memoria Histórica de la Música Religiosa en España ${ }^{1}$, refiriendo las diferentes maneras y estilos de hacer música en las catedrales del reino entre los siglos XVIII y XIX que él denomina antiguo, moderno y mixto, para concluir en lo que él denomina tres formas de la música religiosa de su tiempo, respecto a los elementos que en ella deben emplearse: música a voces solas, voces acompañadas de órgano, cuarteto de cuerda o viento madera y finalmente, voces con acompañamiento de orquesta, señalando los excesos que esta última forma debe evitar.

James Webster publicó en 2004 un interesante trabajo donde planteaba la historia de la música del siglo XVIII, tradicionalmente dividida por la historiografía con la muerte de Juan Sebastián Bach, el final del Barroco y la sucesión de estilos que culminan en el Romanticismo alemán, como un único período². Esta visión admite su justificación en el marco temporal y geográfico europeo, con exclusión de España, donde efectivamente el siglo XVIII se inicia con el imparable ascenso de la ópera italiana y de la música instrumental moderna que comienza a definirse en cánones cada vez más y mejor estructurados dentro del lenguaje tonal hasta su culminación y apertura a las nuevas fantasías sonoras propias del XIX. Su cénit lo marca la época vienesa de Haydn, Mozart y Beethoven, entendidos los tres como superación del clasicismo y por medio de la influencia de la Ilustración, como paulatinos y sucesivos prolegómenos del gran movimiento romántico. Como adelanté, no parece esta teoría aplicable al caso hispano debido a nuestra peculiaridades histórica; el movimiento ilustrado, aunque fundamental como motor del proceso modernizador sufrido por nuestra nación a lo largo del XVIII, no llegó a tener la fuerza de actuación que sí conoció en Francia o en Austria y en ningún caso creemos que pueda confirmarse la existencia de ese primer romanticismo musicalmente tan temprano en nuestra cultura, como si sucede en el ámbito germano.

Otra visión diferente del mismo periodo y contexto es la ofrecida por Daniel Heartz en su análisis del período comprendido entre 1720 y 1780 dentro el marco espacial de las capitales europeas (Nápoles, Venecia, Dresde, Berlín, Stuttgart, Mannheim, París, Londres y finalmente Madrid), definiéndolo en clara relación con el estilo Rococó, como sinónimo de Estilo Galante en música ${ }^{3}$. Al analizar la labor de diversos compositores importantes como es el caso de Gluck, Heartz toca también de modo tangencial, la ciudad de Viena, pero su no inclusión específica en ese breve listado de ciudades marca una intención claramente diferenciadora de la música que allí se producía, es decir la de Haydn, Mozart y Beethoven, dentro de lo que Charles Ronsen ha llamado Estilo Clásico ${ }^{4}$. Varios son los caminos argumentales seguidos por Heartz en su discurso para caracterizar la música del período por él delimitado. Por un lado está la ópera en sus diferentes estilos, de manera muy especial la ópera italiana derivada de modelos barrocos; por otro, las diversas líneas planteadas en su evolución por la música instrumental barroca: concierto, sonata, sinfonía y de manera muy especial música de cámara. Este aspecto, el de la música instrumental, le hace incluir en su estudio, por ejemplo, al violinista Antonio Vivaldi ${ }^{5}$, un autor tradicionalmente considerado netamente

1 ESLAVA, 1860: 89-105.

2 WEBSTER, 2004, 1, 1, (Cambridge, 2004): 47-60.

3 HEARTZ, 2003: 16-23.

4 RONSEN: 1971, traducción al castellano, 1986.

5 HEARTZ, 2003: 188-119. 
barroco, pues entiende su actividad musical dentro del contexto rococó de la Venecia de su época y como creador de una escuela de interpretación sobre este instrumento que entronca con Corelli, de gran trascendencia a lo largo del siglo XVIII, continuada en la España a lo largo de la segunda mitad del siglo XVIII, por medio de la presencia en la corte y Real Capilla de numerosos violinistas oriundos de Italia como es el caso de Miguel Geminiani ${ }^{6}$, hermano de Francesco o la del violinista, ya español, José Herrando ${ }^{7}$, autor de un célebre tratado de violín en línea con las enseñanzas marcadas por sus coetáneos.

Es significativo para nuestro objeto de estudio, que Heartz cuando trata la figura de Boccherini, excede intencionalmente el marco cronológico de referencia -1720-1780-, pues la actividad en la corte madrileña de este instrumentista y compositor le lleva a situarse en la última etapa del siglo XVIII. En tal sentido y como epílogo a su estudio, incluye al "españolizado" músico toscano y autor de célebres fandangos, al lado de Johann Christian Bach (1735- 1782) y de Giovanni Paisiello (1740-1816) denominando a los tres apóstoles del Estilo Galante. Entendemos por tanto, que así como en el centro de Europa se produce después de 1780 la consolidación de un movimiento musical en el que Haydn y Mozart fraguan un lenguaje propio asumiendo en diferente manera algunos de los postulados del Estilo Galante y que este estilo llega a influir en el propio Beethoven ${ }^{8}$, en otros centros periféricos -caso de España- dicho estilo no llegó a cristalizar con similar dimensión, si bien sí se dejaron notar de manera clara sus influencias.

Esta línea argumental marca también una diferenciación sin solución de continuidad entre Estilo Galante y Estilo Clásico respecto a la historia de la música española y de manera concreta sobre la música que se hacía en nuestras catedrales fue expuesta ya en 1980 por Emilio Casares al tratar la música dieciochesca en la catedral de León ${ }^{9}$. En este trabajo pionero sobre el tema, Casares llega a la conclusión de que todo el variado movimiento estético europeo del siglo XVIII es operativo en España (...) haciendo la salvedad de que, al menos en esta Catedral, no se llega a obras que pudiésemos clasificar de grandes creaciones, como sucede en gran parte de Europa. A continuación, en referencia a la obra del maestro Pedro Furió indica que, sobre todo en la Catedral de Oviedo (la obra que queda en León es casi enteramente polifónica), hacen presencia rasgos claramente galantes que hablan de una estética evidentemente diferente, que supone el abandono, o al menos la crisis, del barroco y la presencia de nuevas estéticas. Al maestro Mencía lo categoriza como típicamente clásico, matizando que quizá ello se deba a que este músico entrase en contacto durante los años de estancia en Madrid con las últimas tendencias estéticas, dada la importancia musical de la capital, al reunir en torno a sí a la mayor parte de los creadores de música profana. Como rasgos definitorios de ese "clasicismo", el autor enuncia los siguientes: excesiva simplicidad tonal, el uso de unísonos, búsqueda de tonalidades más fáciles, simplicidad de los solos y sobre todo la pérdida de valor del bajo continuo que pasa a convertirse en una voz más y la tendencia

\footnotetext{
6 SIEMENS HERNÁNDEZ, XI, 3 (Madrid, 1988): 673-679.

7 MORENO, XI, 3, (Madrid, 1988): 556-584.

8 HEARTZ, 2003: 1007.

9 CASARES RODICIO, 67 (León, 1980): 7-87.
} 
marcada hacia la homofonía ${ }^{10}$. Todo ello, menos quizá la simplicidad en muchos solos, son, como veremos características extrapolables al estilo cultivado por Melchor López ya que siendo varias generaciones posterior a Mencía y habiendo recibido su formación musical en la propia corte, dichos rasgos se ven acentuados en su producción musical aunque sin renunciar a esa duplicidad de lenguajes ya aludida que le lleva, como al resto de los maestros de su generación, a seguir cultivando el estilo polifónico al lado de una generosa utilización de la orquesta en la música religiosa.

Con una argumentación similar pero sin llegar a admitir explícitamente la presencia real de un estilo clásico en la música eclesiástica española de la segunda mitad del siglo XVIII, Juan José Carerras en su monografía sobre Francisco Javier García Fájer apodado "El Españoleto" (1730-1809), vuelve a hacer hincapié en las peculiaridades vividas por nuestros músicos con especial influencia de la tensión existente entre el stilus teatralis y el stile antico ${ }^{11}$, un conflicto de el que ya se hizo eco el maestro de capilla barcelonés Francisco Valls hacia $1742^{12}$ y que también recogen el Padre Feijoo y Eximeno en sus escritos ${ }^{13}$. Señala Carreras como rasgos característicos de la música española aplicables al XVIII, la hegemonía de la música sacra y la falta de una tradición musical comparable a ésta, derivando dichas características hacia la reflexión de que, así como en Europa la mayoría de las orquestas mantenidas por la aristocracia tenían asignadas funciones en las catedrales, no tenemos evidencia de lo contrario, es decir de que los músicos catedralicios prestasen sus servicios en los actos seculares ${ }^{14}$, por lo menos de una manera expresa o consentida por las autoridades eclesiásticas, manifiestamente contrarias a ello.

Años después fue López-Calo quien se ocupó de los problemas planteados por el intento de adoptar una terminología estilística que asimilase la música del XVIII español al fenómeno centroeuropeo. De esta manera su ponencia al congreso España en la Música de Occidente, celebrado en Salamanca en septiembre de 1985, llega a interesantes conclusiones que trataremos de resumir ${ }^{15}$ : En la música religiosa española existe a lo largo del siglo XVIII una lenta transición entre los modos barrocos y las nuevas maneras de entender este arte que aportan primero el estilo galante y después el clasicismo vienés. Dicha transición pasa por diversas fases, siendo un hecho fundamental la decadencia a partir del último cuarto de siglo del italianismo imperante y por el contrario, la adopción de otras "maneras internacionales", entre las que llega a nuestras catedrales y se afianza el nuevo concepto de orquesta que deriva consiguientemente en la renovación del repertorio instrumental de las capillas, con especial incidencia del sinfonismo de Haydn.

10 CASARES RODICIO, 67 (León, 1980): 39-40.

11 CARRERAS, 1983: 61-62.

12 MAPA / ARMONICO PRÁCTICO / BREVE RESUMEN / De las principales Reglas de Música / SACADO / DE LOS MAS CLÁSICOS AUTHORES ESPECU- / lativos, y Practicos, Antiguos y / Modernos, / ILUSTRADO / CON DIFERENTES EXEMPLARES, PARA LA / mas fácil, y segura enseñanza del Muchachos. / ESCRIVIOLE EL Ro FRANCISCO VALLS PRESBITERO, Y / Maestro de Capilla Jubilado del la Santa Iglesia del Barcelona. Biblioteca de la Universidad de Barcelona, Ms 783. PAVIA I SIMÓ, 2002: 424-426.

13 Además de las innumerables ediciones del Teatro Crítico de Feijoo y del tratado de Eximeno, Del origen y reglas de la música, sobre este tema recientemente apareció una monografía editada por MARÍN, 2010, donde se recogen diversos estudios en torno la figura del compositor García Fajer, quizás el mejor representante de esta dualidad dentro de la música de su tiempo.

14 CARRERAS, 1983: 62. Sobre García Fajer, vid. GONZÁLEZ VALLE, 2000: 17-56.

15 LÓPEZ-CALO, 1987, vol. 2. Madrid: 3-49. 
Por último, recientemente Paulino Capdepón ha incidido en las peculiaridades de nuestro siglo XVIII musical en general, adoptando para el terreno de la música religiosa una terminología propiamente barroca y que al ser claramente aplicable en nuestro país a la música de toda esta centuria, pone en evidencia esa pervivencia de prácticas aparentemente obsoletas en el tiempo, pero que apuntan hacia la alteridad ya señalada de nuestra historia musical: En la música vocal religiosa predomina una gran diversidad de estilos y procedimientos, incluidos los procedentes del teatro musical italiano, lo que ocasionará la reacción de los compositores y teóricos más apegados a la tradición así como la de los Cabildos catedralicios. Los compositores españoles escribirán sus obras vocales religiosas de manera muy diferente según la obra esté en latín o en español: para las obras latinas se recurre a un estilo solemne y grave, la prima prattica [...] No puede tampoco olvidarse que las obras en latín de los grandes maestros españoles de la época de oro de la música española -Morales, Guerrero, Victoria, Vivanco, Torrentes, Ceballos o Lobo- en ningún momento dejaron de cantarse y copiarse. Por lo que se refiere a las obras en castellano, nos encontramos ante la concepción de la seconda prattica, o estilo moderno, que es el mismo que impera en la música vocal profana: además del uso de la técnica nota contra nota, se busca una mayor adaptabilidad de la música al contenido textual ${ }^{16}$.

A modo de conclusión de esta introducción, podemos afirmar que a lo largo del siglo XVIII los compositores de las catedrales españolas siguieron muy vinculados a la tradición barroca propia de su formación y práctica. Esta potente tradición no fue óbice para que en las capillas musicales se dejasen sentir diferentes oleadas de europeísmo musical, marcadas primero por la llegada de lo italiano y después por la de lo vienés, que no llegaron a cuajar en un estilo propio, similar a lo que sucedía en otros países. Como proceso, las influencias centroeuropeas llegan a nuestras capillas de una manera tardía y se funden con las prácticas allí existentes de un modo parcial y desigual a lo largo de todo el territorio, en función de la propia importancia del centro, focalizándose bajo la poderosa influencia de los modelos cortesanos. Hablamos por tanto de un proceso tardío pero propio, un proceso diferente a lo ocurrido en el resto del continente y por lo tanto importante en la evolución musical hispana; un proceso que además, no pudo culminarse pues su evolución se vio truncada por las dramáticas condiciones (guerra, crisis agrarias) vividas en el reino con la llegada del siglo XIX que derivaron en una crisis generalizada de las capillas musicales. Y es en este contexto que marca el tránsito del XVIII al XIX y que va desde una música religiosa tardo-barroca a una música religiosa marcada por el estilo galante pero nunca plenamente clásica, en el que tenemos que contextualizar los diferentes aspectos del magisterio compostelano de Melchor López que pasamos a analizar.

16 CAPDEPÓN VERDÚ, XVIII, 21 (Oviedo 2011): 11. 


\section{MELCHOR LÓPEZ Y SU ESTILO MUSICAL}

El investigador Joàm Trillo, en sus apreciaciones sobre el estilo musical de Melchor López que acompañan a la grabación de la monumental Misa solemne "Unus Deus" de 1798, indica que es plena y claramente clásico, detectando en él la influencia del estilo italianizante y la de la música de Haydn. Matiza a su vez que es innegable la profunda raigambre española de su música, que aparece claramente si escuchamos la música de los maestros españoles contemporáneos o inmediatamente anteriores. Más adelante este investigador que es a día de hoy el mayor conocedor de la obra de Melchor López, enumera algunas de las características que le llevan a definir el estilo del maestro compostelano en los términos antes referidos: obra con orquesta casi en su totalidad, obras corales concebidas para doble coro, de hechura sencilla y normalmente de carácter homorrítmico, melodías de limpia inspiración y cantabilidad en las partes de los solistas, siendo este aspecto y el de las orquestaciones donde el autor da lo mejor de sí mismo. Añade además que la melodía es la única base de su música y la orquesta es en gran parte su protagonista ya que siempre es tratada con exquisito y transparente sentido del timbre y del equilibrio ${ }^{17}$. Estas afirmaciones fueron matizadas por el autor en la introducción a la edición de la partitura de esta misma composición y en referencia al Quoniam del Gloria, fragmento escrito para solo de bajo con acompañamiento para orquesta obligado de órgano, cuya escritura es más clavicembalística o pianística-típica en España en esta época- que organística, al menos en una mentalidad barroca o moderna, correspondiente a un clasicismo todavía más bien galante ${ }^{18}$.

Esta última frase apuntada sirve de manera adecuada para caracterizar el estilo del autor que nos ocupa: un primer clasicismo muy apegado a los giros y maneras del estilo galante, a pesar de los límites cronológicos en que se mueve dentro del tránsito del siglo XVIII al XIX. Sin embargo, la admiración por la música de Franz Joseph Haydn es sin duda el aspecto que más marcó desde el punto de vista estilístico la actividad musical de la capilla durante su magisterio. Sin temor a confundirnos, podemos afirmar con rotundidad que este maestro nacido en Hueva, formado con José Lidón y que estuvo prácticamente toda su vida al servicio de la catedral compostelana, es uno de los más importantes representantes del estilo del compositor austriaco entre los maestros de capilla españoles de su momento.

Tal aspecto fue observado hace casi un siglo por el también maestro de capilla compostelano, Santiago Tafall Abad en su célebre Discurso póstumo, de ingreso en la Real Academia Gallega. Allí, movido por los principios y prejuicios derivados de su cecilianismo militante y fortalicidos con la promulgación del Motu Proprio de Pío X (1903), realiza la narración del siglo XVIII como época de decadencia de la música religiosa, por la excesiva influencia en ella de las modas operísticas y la aparición y posterior consolidación de la orquesta en las funciones del templo. Ello le lleva a emitir sobre la obra de maestros compostelanos Fray José de Vaquedano, Buono Chiodi y Melchor López, juicios en exceso peyorativos, por no responder a lo puramente religioso y atentar contra su esencia. Sin embargo, Tafall era un buen

17 TRILLO, 2003: 10.

18 TRILLO, 1996: 11. 
conocedor de toda la música conservada en el archivo musical de la catedral jacobea, por lo que se detiene a señalar que dentro de la producción de Melchor López existen coros en sus villancicos que son verdaderos rondós o tiempo de sonata, algunos que no desdeñaría en firmar el maestro alemán ${ }^{19}$, en alusión al autor de Las estaciones o La Creación, aspecto éste que puede verificarse también en sus monumentales misas $^{20}$, escritas en forma de cantata, pero llenas de pasajes donde los instrumentos se combinan con las voces de los solistas, sometidas por momentos a ejercicios propios del belcanto.

López Calo ha señalado cómo ese contacto con el clasicismo musical se produjo con su regreso por motivos familiares a Madrid, en 1794. Para él, tal viaje tuvo una importancia decisiva en la trayectoria artística del compositor pues significó el contacto con el nuevo estilo, precisando que entre 1784 y 1794 en Madrid entró definitivamente en el clasicismo musical, incluidos Haydn y Mozart. Prosigue el investigador indicando que Melchor López volvió entonces transformado en un hombre -y un músico- nuevo: Su estilo musical, a partir de las composiciones del año siguiente, y sobre todo a partir de 1796 -parece ser que él estuvo meditando durante bastantes meses en el camino a seguir- es totalmente distinto, calificando más adelante su Misa Solemne de difuntos "Beati mortui qui in Domino moriuntur" de 1799, como obra escrita en el más puro estilo clásico, tanto en la andadura de sus melodías como en los ritmos y en la sonoridad orquestal; pero es en la concepción misma de la obra, con la recurrencia de sus temas, su equilibrio, su carácter general, verdaderamente mozartiano, donde más se nota este nuevo estilo, que sería el que ya no abandonaría en los años sucesivos ${ }^{21}$.

Otros datos que permiten sostener las afirmaciones antes referidas vienen confirmados por hechos singulares: en primer lugar, indicar que el propio maestro compostelano reconoció la admiración que profesaba por el gran sinfonista vienés por medio de una Misa en re mayor, cuya partitura revela que fue copiada en Madrid el año de1794 y cuyo título -como la partitura, manuscrito por Melchor López- especifica ser del $S^{o r}$ Giuseppe Haydn ${ }^{22}$. Se trata en todo caso, de una misa apócrifa que no se identifica con ninguna de las misas catalogadas por Hoboken, pero escrita en los patrones del autor, dentro de un estilo clásico en rápida evolución hacia su culminación vienesa. Un caso similar, mucho más interesante es el de la Lamentación primera para la tarde del Jueves Santo de 1796 que Melchor López escribe ya a su vuelta de Madrid y que como él mismo indica esta sacada del Stabat Mater del Sor Hiuseppe Haydn ${ }^{23}$, pues se basa en el primer número de esta composición, posiblemente la más célebre del vienés. Finalmente y por su significado como traspaso de contextos y estilos, es de importancia indicar la existencia en el archivo compostelano de un Villancico $6^{\circ}$ a dúo de tiple y tenor con acompañamiento de violines, viola, fagot y bajo, del que sólo se conservan las partichelas, muy posiblemente copiadas por nuestro maestro y donde,

19 TAFALL ABAD, XXVI, 131 (La Coruña, 1931), passim. LÓPEZ-CALO, 1993: 373.

20 LÓPEZ-CALO, 1992: 243, núms.1.774-1.785. Aunque las partes de estas composiciones se encuentran en la catedral de Santiago, el volumen encuadernado que contiene las partituras, se halla en la catedral de Lugo.

21 LÓPEZ-CALO y TRILLO, I, (Santiago de Compostela, 1987): 12.

22 LÓPEZ-CALO, 1993a: 245, núm. 1.780.

23 Archivo de música de la catedral de Santiago de Compostela; Leg. 57/10 y vol. 1.394, fols. 131r-138v. LÓPEZ-CALO, 1992: 319-320; núm. 887 y (1993a): 123, núm. 1.378. 
como en las obras anteriores, con su cuidada caligrafía, aparece la leyenda Del $S^{\text {or Giuseppe Haydn }}{ }^{24}$. No se trata ya de la influencia externa del estilo de Haydn sobre la manera de concebir la música de nuestros compositores, sino de un intento eficaz por adaptar el estilo cultivado por este maestro a un tipo de pieza tan propio de la idiosincrasia hispana como es el villancico, un género cuya composición a finales del siglo XVIII estaba en franco declive.
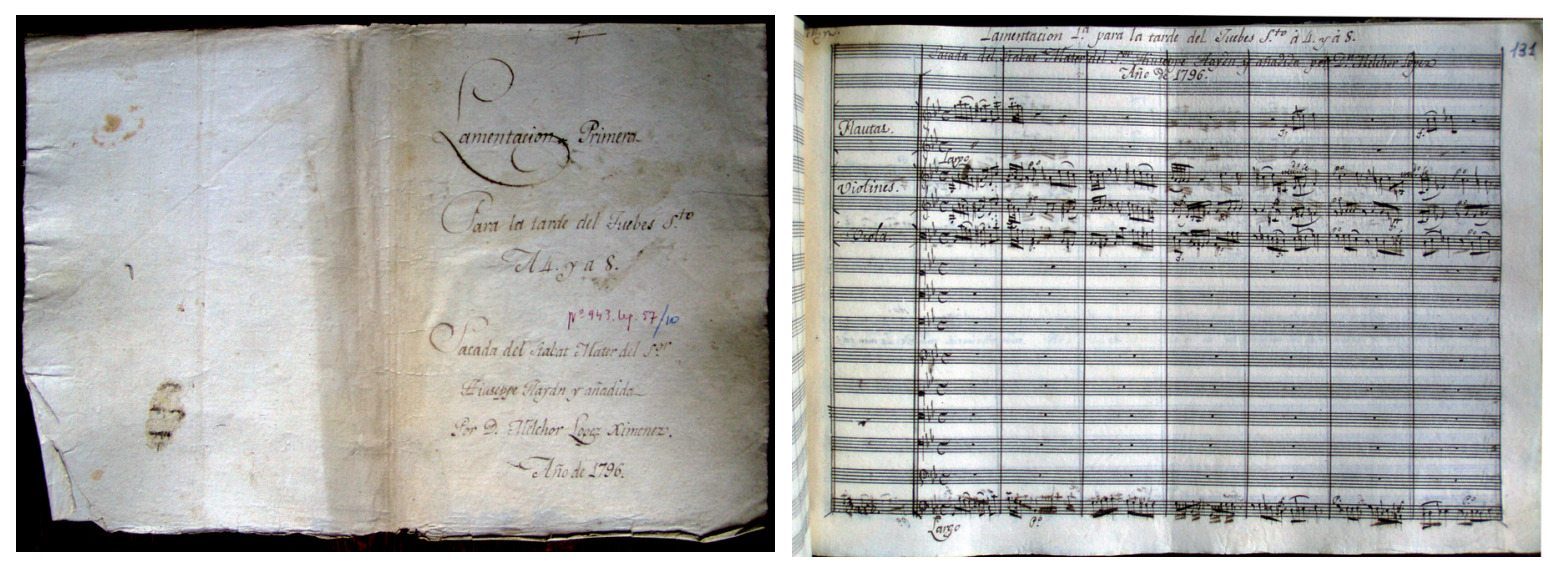

Imágenes 1 y 2: Melchor López: Portada que contiene las partichelas -autógrafas de Melchor López- de la Lamentación primera para la tarde del Jueves Santo de 1796, sacada del Stabat Mater del Sor Hiuseppe Haydn. Archivo de música de la Catedral de Santiago, Leg. 57/10 e inicio de la partitura autógrafa del maestro correspondiente la misma composición (Lamentación primera a 4 y a 8 para la tarde del Jueves Santo de 1796 sacada del Stabat Mater del Sr. Hiuseppe Haydn). Archivo de música de la catedral de Santiago de Compostela. Vol. encuadernado 1.394, fol. 131r.

La admiración que Melchor López profesó por la música de Haydn es la que le permitió trabajar siempre desde un ideal sonoro ciertamente "clásico" que se refleja en la escritura musical de sus obras, particularmente en la escritura equilibrada de la orquesta donde se incluye en un alto porcentaje el uso de la viola y en ocasiones también la diferenciación entre la parte del violón, ejecutada ya por los violonchelos y la del bajo, encomendada al contrabajo, instrumento existente en la capilla desde la década de 1770 y del que en el propio archivo se conservan dos ejemplares anónimos que responden a la tipología de este instrumento a finales del XVIII ${ }^{25}$. Lograr y mantener en el tiempo tal orquesta no hubiese sido posible sin el empeño del maestro por contar siempre con ella, preocupándose, como refleja la abundante documentación manejada, por asesorar al Cabildo en todo cuanto afectase a la plantilla de voces e instrumentos y

24 Archivo de música de la catedral de Santiago de Compostela; Leg. 157/7. LÓPEZ-CALO, 1993b: 194; núm. 3.178. 25 GARBAYO MONTABES, 2003: 293-304. 
también en el propio interés mostrado por el gobierno de la catedral por contar con una capilla de música de calidad que, mientras la circunstancias lo permitieron, fuese de las más notables del reino.

Como señala Carlos Villanueva, el esplendor de la capilla se resiente a partir, especialmente, de 1808, con Santiago ocupado por las tropas francesas y paralizada por los impuestos y robos que padecerá la iglesia compostelana, que sufre directamente la falta de recursos de la mesa de la música: con las siguientes reducciones de salarios y la progresiva desbandada de músicos que irán buscando una mejor solución a su vida laboral. El Maestro de capilla, sin embargo, hasta última hora, seguirá escribiendo para la gran plantilla de su ideal sonoro (que ciertamente no se correspondía con el sonido real de la orquesta con la que tuvo que trabajar hasta su muerte) si bien el grueso de su obra está datada antes de $1805^{26}$.

Directamente ligado a esa grandeza de la capilla mencionada por Villanueva y por lo tanto a la presencia de una orquesta numerosa y equilibrada, formada por músicos notables -fundamentalmente violinistas-, procedentes en muchos casos de la propia corte y con formación novedosa en estilo, permitió renovar el repertorio instrumental que el conjunto interpretaba en misas, vísperas, siestas y otras funciones, con un importante peso de la música sinfónica de Haydn, verificado como veremos por la renovación del repertorio obrada en los últimos años del XVIII. Analizaremos por tanto en lo que resta de trabajo estos dos fenómenos, unidos por una recíproca relación causa-efecto: La evolución de la orquesta de la capilla de música de la catedral de Santiago en tiempos de Melchor López y la renovación de su repertorio instrumental en el último cuarto del siglo XVIII y primeras décadas del XIX.

No quiero concluir este apartado sin hacer una breve referencia a otro aspecto de la música de Melchor López que lo sitúa como un músico de su tiempo, en nada ajeno a lo que sucedía fuera de las iglesias, en los teatros y saraos. Nos referimos a su conocimiento de la ópera italiana, verificable en el propio tratamiento de las partes solistas de sus composiciones religiosas, algunas de las cuales son verdaderas arias da capo, así como en la composición ex profeso entre 1792 y 1819, de un importante corpus de arias profanas sueltas para las cuatro voces, pero fundamentalmente para tiple, sobre textos tomados principalmente de libretos de Pietro Metastasio y de un gran virtuosismo vocal. Entre los textos utilizados por el maestro compostelano en estas arias, hemos identificado en un primer acercamiento, fragmentos de los siguientes libretos: Adriano in Siria (1732), Artaserse (1730), Didone abbandonata (1724), Ezio (1728), Issipile (1732), Semiramide ricconosciuta (1729), Siroe, Re di Persia (1726), e incluso del muy posterior Ruggiero ovvero l'eroica gratitude (1771) ${ }^{27}$. Es este un aspecto que todavía se halla sin estudiar pero muy interesante dentro de la obra del compositor, dado su carácter excepcional en el conjunto de su producción, que sorprende por el perfecto manejo que realiza de los mimbres de la ópera seria italiana; también por su funcionalidad ya que están escritas para ser tocadas por los músicos y cantantes de la capilla en las academias que debían celebrarse en los palacios y casas de la nobleza más ilustrada de la ciudad, así como ocasionalmente en los teatros ${ }^{28}$, dentro de representaciones mayores.

26 VILLANUEVA, 2011: 22.

27 Sobre Metastasio además de las ediciones de sus obras realizada por GAVAZZENI, 1978 y FUBINI, 1977 se han consultado también los trabajos de BENZI, 2005 y CHEGAI, 1998.

28 LÓPEZ-CALO, 1993a: 224-231; núms. 1.713-1.741: 235-236, 238 y 241; núms. 1.752, 1.758 y 1.766. 


\section{EL NUEVO REPERTORIO INSTRUMENTAL DE LA ORQUESTA DE LA CAPILLA DE MÚSICA DE LA CATEDRAL DE SANTIAGO DE COMPOSTELA, BAJO EL MAGISTERIO DE MELCHOR LÓPEZ}

Diversos trabajos en las últimas décadas han abordado diferentes puntos de vista relativos a la composición y evolución de la capilla musical compostelana en los años de Buono Chiodi y Melchor López. Todos ellos inciden en los grandes modernización sufridos experimentada por su orquesta, concluyendo que, al menos durante los últimos años del magisterio del músico italiano y los primeros de sus sucesor, la catedral contó con un nutrido grupo de voces e instrumentistas, de notable nivel en muchos casos, que permitió a dichos maestros componer e interpretar un repertorio musical ambicioso.

Refiriéndonos a la formación instrumental del conjunto y en resumen, ofrecemos un cuadro explicativo, donde pueden verificarse los siguientes hechos:

- Desde 1778 aproximadamente, la orquesta de la catedral de Santiago de Compostela contó con una nutrida plantilla instrumental que le permitió mantener de manera estable una formación compuesta por la cuerda -incluyendo la viola- además de una pareja de oboes y otra de trompas, a los que se unieron ocasionalmente otros instrumentos como las flautas o los bajones. Dicha situación fue heredada por Melchor López al hacerse cargo del magisterio.

- Una buena parte de los componentes de dicha orquesta que habían entrado a servir en el templo durante el magisterio de Chiodi, permanecieron en la misma durante el magisterio de Melchor López. Esto es especialmente verificable antes de 1800.

- Un importante número de instrumentistas - principalmente violinistas, pero también oboes y trompas- eran de procedencia italiana, atraídos a Santiago sin duda por la presencia de Chiodi y la propia fama del centro, musicalmente hablando

-También se detecta el paso por la capilla de importantes violinistas procedentes de diferentes centros peninsulares, pero muy especialmente de la corte madrileña.

Como sucedió en todas las iglesias españolas a lo largo del XVIII las maneras musicales europeas que llegaban a sus capillas se acabaron combinando con las peculiaridades que caracterizan nuestras prácticas musicales, originando un estilo musical propio que partiendo del barroco patrio, pasa por un revestimiento de internacionalización y finalmente llega hasta las puertas del mismo Estilo Clásico. En música instrumental, el repertorio propio de ministriles que a su vez había suplantado en muchos casos el papel del órgano en la liturgia, dio paso a un tipo de música orquestal que Valls en su Mapa Harmónico encuadra dentro de lo que denomina Estilo Phantástico ${ }^{29}$, y donde engloba sinfonías oberturas, sonatas y $\operatorname{conciertos}^{30}$. Fue primero la música en el estilo de la sonata y del concerto italiano, tanto en su variedad de concerti grossi ${ }^{31}$ como en la de

29 PAVIA I SIMÓ, 2002: 424-426; MARTÍN MORENO, 1976-1977:157-194.

30 Sobre la pervivencia de estos modelos en la música de nuestras catedrales y su adptación sobre formas propiamente hispanas, así como sobre su utilización en las siestas, vid. EZQUERRO ESTÉBAN, 2004: 7-12 y 13-19.

31 GONZÁLEZ MARÍN, 2002: XLIII-L; 2007: 573-635; CARRERAS, 1983: 52. 
concerto o sonata solista cultivada por Corelli, Vivaldi, Albinoni y sus seguidores. Este tipo de música no era desconocido en la catedral de Santiago y como hipótesis, creemos que debió ser traída al templo por Chiodi en su traslado desde Italia o por algunos de los violinistas italianos que tocaron bajo su magisterio. Conservamos en el archivo de la catedral de Santiago un revelador memorial, citado por López-Calo, titulado Razón de las obras de música que se entregaron al señor maestro de capilla don Melchor López y fechado en 3 de diciembre de $1792^{32}$. El documento es un largo listado de composiciones religiosas de autores españoles -incluidos los maestros de otras catedrales gallegas- y músicos italianos, en cuya segunda parte se hacen importantes referencias a obras de música instrumental. De esta manera, al lado de música de Domingo Tarradellas, Pergolesi, "maestro Leo" o Vicente Roel -músico activo en las capillas de Lugo, Mondoñedo y Santiago-, se indican con todo detalle las siguientes colecciones de música instrumental:

Año 1783
Pedro Iturralde, Manuel Neyra,
José Espada, Cayetano Pichini,
violines
Santiago Leydeck,
violin (¿y viola?)
Santiago Calvo, bajón
y viola
Juan José Perrault
(Peroli), violín y oboe
Pedro Estévez, violón
Marcos Martínez,
contrabajo
Antonio Dalmases y
Alejandro Muiños,
oboes
Alejandro Muiños,
oboe
Gaspar Servida y José
(Servida) Francapani,
trompas
Pedro Theo y Pedro
Rey, bajones
Pedro Rey, bajón
Francisco Sabatán
y Antonio Bueno,
órganistas.

\begin{tabular}{|c|c|}
\hline Año 1791 & Año 1800 \\
\hline $\begin{array}{l}\text { Pedro Iturralde, Manuel } \\
\text { Neyra, José Espada, } \\
\text { Cayetano Pichini, Juan José } \\
\text { Perrault, Francisco García, } \\
\text { Sebastián Siquert, Miguel }\end{array}$ & $\begin{array}{l}\text { Pedro Iturralde, Manuel } \\
\text { Neyra, Francisco Garcia, } \\
\text { Sebastián Siquert, Juan } \\
\text { Carnicer, violines }\end{array}$ \\
\hline Reynaldi, violines & $\begin{array}{l}\text { Silvestre Torrado, Ramón } \\
\text { de Torres, violones }\end{array}$ \\
\hline $\begin{array}{l}\text { F. Javier Moreno, violín ( ¿y } \\
\text { viola?) }\end{array}$ & Marcos Varela, contrabajo \\
\hline $\begin{array}{l}\text { Pedro Estévez, Silvestre } \\
\text { Torrado, violones }\end{array}$ & Antonio Dalmases, oboe \\
\hline Marcos Varela, contrabajo & $\begin{array}{l}\text { Alejandro Muiños, oboe } \\
\text { (¿y flauta?) }\end{array}$ \\
\hline $\begin{array}{l}\text { Antonio Dalmases, } \\
\text { Alejandro Muiños, oboes }\end{array}$ & $\begin{array}{l}\text { José Servida, Gregorio } \\
\text { Montoto, Joaquín Badía, } \\
\text { Francisco Badía, trompas }\end{array}$ \\
\hline $\begin{array}{l}\text { Gaspar Servida, José } \\
\text { Francapani (Servida), } \\
\text { trompas }\end{array}$ & $\begin{array}{l}\text { Pedro Rey, Francisco } \\
\text { Morán. José María } \\
\text { Herrero, bajones }\end{array}$ \\
\hline $\begin{array}{l}\text { Pedro Rey, Francisco Morán, } \\
\text { bajones }\end{array}$ & $\begin{array}{l}\text { Santiago Calvo, bajón ( ¿y } \\
\text { viola?) }\end{array}$ \\
\hline $\begin{array}{l}\text { Santiago Calvo, bajón (¿y } \\
\text { viola?) }\end{array}$ & $\begin{array}{l}\text { José Maria Herrero, } \\
\text { Antonio Bueno, Tomás }\end{array}$ \\
\hline $\begin{array}{l}\text { Francisco Sabatán, Antonio } \\
\text { Bueno, Tomás Prieto, }\end{array}$ & Prieto, organistas \\
\hline
\end{tabular}

$\begin{array}{ll}\text { Año } \mathbf{1 8 1 8} & \text { Año 1823 }^{1} \\ \begin{array}{l}\text { Isidoro Llanos, Sebastián } \\ \text { Siquert, Francisco Garcia, } \\ \text { Francisco Carnicer, Manuel } \\ \text { Neyra, Nicolás Gestal, violines }\end{array} & \begin{array}{l}\text { Juan Curtié, Sebastián } \\ \text { Siquert, Francisco } \\ \text { Badia, Francisco } \\ \text { Garcia, Nicolás Gestal, } \\ \text { violines }\end{array} \\ \begin{array}{l}\text { Francisco Badia, violin (y } \\ \text { viola?) }\end{array} & \text { Silvestre Torrado, violón } \\ \text { Silvestre Torrado, violón } & \begin{array}{l}\text { Andrés Muiños, oboe (¿y } \\ \text { flauta?) }\end{array} \\ \text { Francisco Calvete, contrabajo } & \begin{array}{l}\text { Joaquin Badia, trompa (¿y } \\ \text { violín?) }\end{array} \\ \text { Antonio Chic, oboe } & \begin{array}{l}\text { José Simoneti, bajón (¿y } \\ \text { oboe?) }\end{array} \\ \text { Andrés Muiños, oboe (y flauta?) } & \begin{array}{l}\text { Tomás Prieto, Torcuato } \\ \text { Hermida, Juan Ferro, } \\ \text { organistas }\end{array} \\ \text { Francisco Morán, trompa } & \\ \text { Joaquín Badía, trompa y violin } & \\ \text { Santiago Mercado, bajón (¿y } \\ \text { viola?) }\end{array}$

Imagen 3. Tabla comparativa de la plantilla de la orquesta de la capilla de música de la catedral de Santiago de Compostela en varios momentos significativos: 1778 (última etapa del magisterio de Buono Chiodi), 1791 (época de esplendor de la misma, ya durante el magisterio de Melchor López), 1800 (comienzo de su decadencia), 1818 (recuperación) y 1823 (decadencia irreversible, ya tras la muerte del maestro López). Fuente: Archivo Capitular de la catedral de Santiago de Compostela: Libros del Depósito de la Música.

32 Razón de las obras de música que se entregaron al señor maestro de capilla don Melchor López, Archivo capitular de la catedral de Santiago de Compostela, Leg. Capilla de Música. Instrumentistas (1734-1782); LÓPEZ-CALO, $1993 c: 287$. 
La Stravaganza a (sic) don Antonio Vivaldi, completa en 5 libros / Sei concerti di don Antonio Vivaldo, en 6 libros, ópera undécima / Balleti e sonate, da Tomasso Albinoni, en 4 tomos, opera 8 / Concerti, del signore Girolamo Laurenti, en 4 liboros, incompleta, ópera prima / Concerti, del signore Angelo María Scaccia, ópera prima, completa en 6 tomos.

Todo parece indicar que esta música que estaba desde hace años en posesión del Cabildo se encontraba entonces en desuso y conociéndose seguramente su interpretación dentro de la catedral durante el magisterio de Chiodi, se entregaba a su sucesor con la clara intención de que volviese a ser tocada por la orquesta. Se trata en todo caso, de música estilísticamente alejada de la del maestro López; obras que se mueven en los cánones clásicos y avanzados del concierto y la sonata a solo de la escuela veneciana (Vivaldi, Albinoni, Laurenti, Scacchia), pero que encaja perfectamente en las disposiciones capitulares que las actas recogen en varias ocasiones para que los músicos y particularmente el primer violín y el primer oboe de la orquesta, en algunas funciones tocasen "a solo", o "o sonatas". A falta de documentación más explícita, no podemos verificar con absoluta certeza el uso de esta música en la catedral, pero sí que los instrumentistas de la orquesta tenían la obligación de tocar sin las voces en determinadas solemnidades. Así, durante el magisterio de Chiodi, el cultivo del concierto y de la sonata encajan perfectamente en la disposición capitular sobre música instrumental dada en capítulo de 23 de agosto de 1774, cuando se observó (...) el acta tocante a que los músicos, alternativamente, principiando Peroli, toquen conciertos en todas las funciones clásicas y de reliquias, lo que hagan cumplir los señores contador. Pocos meses después, el 25 de octubre, se volvió a insistir en el mismo asunto y se ordenó que el maestro de capilla haga que en todas las funciones clásicas y de reliquias se toquen conciertos, formando solo y dando principio en la de Santos, y al que eligiere y no lo hiciere se le descuenten quince días. Pero el acuerdo más significativo sobre la presencia de la música instrumental dentro del ceremonial litúrgico de la catedral, tuvo lugar el 28 de septiembre del año siguiente. Entonces y por tercera vez, se volvió a llamar la atención al maestro de capilla para que dispusiese que en las funciones solemnes se toquen por Peroli, Laideq y Canchiani, conciertos, alternando cada uno, y que en los días de las reliquias toquen aberturas o algún concierto, según lo determinare el maestro ${ }^{33}$.

Fuera de estos datos, no conservamos en la catedral música instrumental que se tocase con seguridad durante el magisterio del abate Chiodi, salvo las partichelas autógrafas, de una Sinfonía concertante para cuarteto de cuerda y orquesta, atribuida por López-Calo a él y que ofrece muestras de haber sido muy utilizada a lo largo del tiempo ${ }^{34}$. En esta curiosa obra, a pesar de lo que sería evidente en un cuarteto de finales de la década de 1770 en que creemos se escribió esta composición precisamente coincidiendo con la llegada de la viola a la catedral, como hemos demostrado en anteriores trabajos, el verdadero papel solista es ejecutado por la viola y el violonchelo, cuyas partes tienen una dificultad de ejecución más que notable.

33 Archivo capitular de la catedral de Santiago de Compostela; Actas capitulares, vol. LVIII, fol. 111v (23/VIII/1774), fol. $119 \mathrm{v},(25 / \mathrm{X} / 1774)$ y fol. 164 (28/IX/1775).

34 LÓPEZ CALO y TRILLO, 1992: 5; PÉREZ BERNÁ, XXI, 2, (Madrid, 1998): 553-572. 
Fallecido el músico italiano, como nos cuenta nuevamente Santiago Tafall en su Discurso de ingreso en la Real Academia Galega; durante el tiempo de los maestros López y Palacio el empleo de la orquesta en las funciones del culto llegó a rebasar los límites de lo prudente y rayar en el abuso. Durante el octavario del Corpus, además de tocar la misa mayor, había lo que llamaban siesta, esto es: de doce a una tocaba la orquesta conciertos, cada día un solista de un instrumento, alternando con el canto de villancicos; de una a dos cuartetos clásicos, por los instrumentos de cuerda, y de dos a tres el órgano sólo. Por la tarde, antes de la Reserva, se cantaba un aria con coros y orquesta y, aparte de esto en todas las solemnidades, al ofertorio de la misa se tocaban sinfonías, conciertos, etc. Todo esto se hacía por realzar el esplendor del culto, y hasta tal punto se aquilataban los detalles que los profesores de la orquesta estaban obligados a vestir el frac siempre que tenían que actuar en el coro de la iglesia. No podía ser más recta ni más digna de alabanza la intención del Cabildo que tales cosas disponía; pero hemos de reconocer que no iban acertados, a pesar de su buen celo, y el tiempo se encargó de hacer presente esta verdad, no sólo con la depuración del gusto artístico, que iba poniendo en evidencia ciertos anacronismos, sino con los abusos del poco devoto público, que concurría a estos actos más bien a pasar el rato oyendo música que a dar culto y reverenciar a Dios con la modestia y el recogimiento propios del lugar santo. El mismo Cabildo, convencido de estos inconvenientes, suprimió las audiciones musicales, semiconciertos sacros, y limitó el uso de la orquesta a los actos litúrgicos que lo permiten ${ }^{35}$.

El juicio de Tafall parece mezclar los años de Melchor López, con la experiencia vivida por él en los años finales del XIX, y así se deduce de la detallada descripción de la indumentaria con que se obligaba a actuar a los músicos en las funciones, muy alejada de las tradicionales ropas de coro. Pero en todo caso, demuestra que la costumbre de tocar música instrumental y principalmente sinfonías, conciertos y cuartetos dentro de la iglesia durante las siestas y otras funciones se prolongó en Santiago durante la segunda mitad del siglo XIX.

El magisterio de Melchor López apunta también importantes documentos que señalan cómo hacia finales del siglo XVIII se produjo un cambio sustancial en el repertorio instrumental que tocaba la orquesta de la catedral, con especial incidencia de la irrupción en él con fuerza de la música sinfónica moderna en especial la de Franz Joseph Haydn. Sabemos, por ejemplo, que de todos los músicos que conformaban la orquesta de la capilla a lo largo de esta nueva etapa, el violinista cuyo origen desconocemos, Sebastián Siquert fue quien más peso llevó en todos los aspectos relacionados con la presencia de la música instrumental en el culto. Sobre la misión que Siquert desempeñaba en la capilla y el celo con que tomaba este su labor, nos ofrece valiosos datos un memorial que dirigió al Cabildo hacia finales de 1798, defendiéndose de graves denuncias que vertían sobre su honestidad los demás músicos de la capilla, relacionadas con toda una serie de problemas relativos al reparto de los fondos de la fundación pía que mantenían entre ellos para sufragarse sus entierros y los de sus familiares. En este documento Siquert, en un intento de probar su buena fe ante el Cabildo, hace constar específicamente, que (...) emplea diariamente muchas horas en estudiar, que sacrifica una parte de su renta en papeles de música,

35 TAFALL ABAD (1931), 134; LÓPEZ-CALO; 1993c: 376-377. 
que toca conciertos en los más de los días de reliquias (...) sólo con el fin de adelantar ${ }^{36}$. El documento nos lleva a pensar en el importante peso que este músico tuvo en la renovación en el repertorio de música instrumental experimentado en Santiago en el tránsito del siglo XVIII al XIX, revelando que además de cumplir con su obligación de interpretárla, también era él quien en ocasiones la adquiría. Hasta ese momento dicha labor había sido cometido del violinista y violonchelista francés, Juan José Perrault -conocido en la catedral, a la manera italiana, como Peroli, - activo en la capilla a lo largo de todo el magisterio de Chiodi. Ello se evidencia en otro memorial posterior donde Siquert explica que, habiendo sido admitido por segundo violín y primero en las ausencias de Peroly (sic), tuvo que comprar mucha música moderna para tocar y componer varios conciertos, en que ha desperdiciado mucho dinero y estudio, como Vuestra Señoría Ilustrísima conocerá por el sobresaliente lucimiento que experimentan las funciones ${ }^{37}$. Al año siguiente hallamos otro documento similar que hace referencia a esta misión en términos parecidos, indicándonos que Siquert venía desempeñando cerca de dos años la plaza de primer violín por indisposición de don Juan Perrault y que con ese motivo, para concurrir con la música necesaria tanto en las festividades del Corpus como para las demás funciones de esta Santa Iglesia, se había visto obligado a realizar varias compras de música ${ }^{38}$.

La adquisición de partituras para la catedral por Siquert está parcialmente documentada en las actas capitulares y en una serie de memoriales que a continuación detallaremos. Así, en el año de 1799 Siquert notificó al Cabildo haberle llegado una remesa de música para uso de las festividades de esta Santa Iglesia, las que no se podían tocar sin hacer antes de ellas las pruebas correspondientes. Le suplicaba además que se dignase ordenar a todos los músicos [que] concurriesen dos días en una semana a casa del maestro de capilla para dicho fin $^{39}$. $\mathrm{Al}$ año siguiente, el 29 de octubre, Siquert volvió a remitir una nota similar, donde figuraba un listado preciso de aquellas obras que consideraba necesarias para el servicio de la iglesia. El Cabildo acordó sin dar demasiadas explicaciones suspender la compra de dichas partituras, pero afortunadamente conservamos el listado original de las mismas, así como una serie de noticias posteriores que nos llevan a pensar que esta partida de música se hallaba ya en ese momento en posesión del violinista ${ }^{40}$.

En efecto, un documento del archivo catedralicio, titulado en su cabecera Nota de la música para Don Sebastián Siquert, ofrece el siguiente listado de composiciones, fundamental para establecer el conocimiento amplio que este violinista tenía de la música de su momento y del tipo de música instrumental

36 Archivo capitular de la catedral de Santiago, Leg. Capilla de Música. Ss. XVII-XIX. 23/II/1791.

37 Archivo capitular de la catedral de Santiago de Compostela, Leg. Capilla de música. Instrumentistas (1734-1782);

38 Archivo capitular de la catedral de Santiago de Compostela, Leg. Capilla de Música. Instrumentistas (1734-1787); 13/VIII/1792.

39 Archivo capitular de la catedral de Santiago de Compostela, Actas capitulares; vol. LXIII, fol. 67, 26/I/1799.

40 La última noticia de las actas referente a la compra de música instrumental para la capilla por parte de Sebastián Siquert, pertenece al 14 de enero de 1817, cuando el violinista solicitó dos mil reales anticipados a descontar en dos años y dice que los necesita para comprar música. En esta ocasión el Cabildo, con otras prioridades a la hora de reconstruir la capilla tras la difícil etapa que acababa de pasar, le respondió con una negativa. Archivo capitular de la catedral de Santiago de Compostela, Actas capitulares, vol. LXVI, fol. 350, 14/I/1817. 
que se pudo interpretar en nuestra catedral en el tránsito en los últimos años del siglo XVIII y primera década del XIX:

Conciertos de Viotti, núms 1, 2, 3, 4, 5, 6, 7, 8, 9, 10, 11, 12, 13, 14, 15, 16, 17 / Conciertos de Jarnovicik, núms 1, 2, 3, 4, 5, 6, 7, 8, 9, 10, 11, 12, 13, 14, 15, 16, 17, 18, 1941 / Conciertos de Mestrino núms $1,2,3,4,5,6,7,8,9,10$ /

Cuartetos de Pleyel núms 1, 2, 3, 4/ ídem núm. 7, libro 1 a 2 / ídem núm. 11, libro 1 a 2 / ídem núm. 12, libro 3 a 4 / ídem núm 15, libro 1 a 2 / ídem núm. 8, Dedicados al Rey de Nápoles / ídem, núm. 30, Dedicados al Rey de Prusia / Cuartetos de Viotti, núm. 1-242.

Sinfonías de Pleyel. Núm. 1, 2, 3, 4, 5, 6, 7,8, 9, 10, 11, 12, 13, 14, 15, 16, 17, 18, 19, 20, 21, 22, 23, 24, 25, $26^{43}$ / Sinfonías de Girovez ${ }^{44}$ núm. 7, 8, 9, 10, 11, 12, 13, 14, 15, 16, 17, 18 / Sinfonías de Haydn núm. 35, 36, 37, 38, 39, 40 / ídem obra 54 núm. 1, 2, 3, 4, 5, 6.

Sebastián Siquert, el autor del listado, añade al final una nota aclaratoria del mayor interésde interés, señalando que todas estas obras tendrán de coste en Madrid seis mil reales, (...) pero en Lisboa, cuyo almacén es el más surtido de la Europa, se comprarán con más equidad, como lo ha experimentado el exponente en las que ha mandado venir para su servicio por medio del corresponsal que tiene en Oporto $^{45}$.

La importancia de este documento radica por un lado en testimoniar el cambio de gusto musical que ya se había obrado en la capilla, más acorde con el momento que se vivía en el resto del continente así como el conocimiento que este violinista y encargado de la música instrumental en la catedral, tenía de la música de su tiempo; por el otro, parece demostrarse en ese último párrafo que que la música le llegaba a Siquert vía Portugal, concretamente desde Lisboa, aunque quizá también se hubiese realizado alguna adquisición de música en la vecina ciudad de Porto como él mismo afirma. Esto, evidentemente, no era un hecho casual, sobre todo teniendo en cuenta que, tras la Revolución Francesa, Londres se había convertido en el gran centro europeo editor de música, un hecho que dadas las importantes relaciones comerciales y políticas existentes entre portugueses e ingleses, convirtió a Lisboa en un centro distribuidor de importancia.

Sabemos además que en la capital lusitana, Siquert contaba con un corresponsal de excepción que en su momento había pretendido entrar en la catedral de Santiago, animado por el violinista: el violinista y compositor José Palomino. Nacido en Madrid en 1757, Palomino fue muy joven violinista de la Capilla Real española y a partir de 1774 pasó a servir en la de los reyes portugueses donde desarrolló una fecunda actividad como instrumentista y compositor tanto de música vocal como de música instrumental. Desde el país vecino y animado por Siquert -quien por razones que no hemos podido verificar, pero que apuntan a una antigua amistad, tenía verdadero empeño en que Palomino entrase a tocar en la capilla y

41 NUNAMAKER, 1968: passim.

42 WHITE, 1985: 49-54.

43 . BENTON, 1977: 27-61, núms. 121-147.

44 DOENBERG, XLIV, (Oxford, 1963): 21 y ss.

45 Nota sobre la música para D. Sebastián Siquert, Archivo capitular de la catedral de Santiago, Leg. Capilla de Música. Instrumentistas (1734-1787); ca. 1791. 
así lo había demostrado al Cabildo en repetidas ocasiones- Palomino pretendió servir en la Catedral de Santiago como primer violín en $1798^{46}$. Al no verse cumplido este propósito, cuando las tropas napoleónicas invadieron el reino vecino y al huir los reyes a Brasi y su Real Capilla se dispersó, Palomino aceptó el cargo de Maestro de Capilla de la catedral de Las Palmas, trasladándose a esta ciudad insular, donde falleció en $1810^{47}$.

Los escasos testimonios que han quedado en el archivo de la catedral de Santiago de la correspondencia entre Siquert y Palomino, parecen indicar que se profesaban gran amistad, aspecto que quizá indique un conocimiento anterior, y que conllevaría cuando menos la sospecha del paso de Siquert por las Cortes, española o portuguesa ${ }^{48}$, un hecho que influiría enormemente en la visión que tenía de la música de su tiempo. Los documentos que presentamos, demuestran además que Palomino enviaba regularmente a su contacto en Santiago partidas de música desde su residencia lisboeta y que este se le abonaban una vez recibidas de modo particular, aunque con la ayuda del Cabildo. Pero el pago de una partida, no se hizo efectivo en torno a las Navidades de 1798, cuando Palomino reclamó a Santiago que le devolviese una serie de papeles que había enviado, que nunca habían sido abonados y que consideraba, por tanto, de su propiedad ${ }^{49}$.

Sobre el repertorio concreto conservado de música instrumental de estos años que se custodia en el archivo musical del templo, indicar que se guarda una interesante colección de seis sinfonías manuscritas que López-Calo identifica como de procedencia italiana ${ }^{50}$, al lado de otras partituras que, el musicólogo indica, fueron traídas por Chiodi ${ }^{51}$ desde Italia. Independientemente de que esta hipótesis sea o no posible, nosotros creemos que esta música estuvo también vigente durante el magisterio de Melchor López, como buena parte de la obra que el abate italiano dejó a su muerte. En concreto se trata de una sinfonía en fa mayor de Piccini, otra en la misma tonalidad de Astarita, y cuatro en re mayor de Paisiello, Sacchini, Anfossi y Naumann, respectivamente. Además de ellas, con posterioridad a la última catalogación de López-Calo, localizamos en el archivo otro importante conjunto de obras similares en magnífica edición parisina de Bailleux y cuya portada dice expresamente que se trata de Six Overtures a grande orchestre, tirées des plus beaux operas italiens, tels que Le due comtesse, La Frascatana..., pour deux violóns, un alto, une basse, deux flutes ou hautbois, les cors sont ad libitum, composées par Messieurs Paisiello, Trajetta, Pugnani, et Sacchini, Meses au Jour par Mr. Bailleux, chez Mr Bailleux, Md. de musique ordinaire Rue St Honorè a la Regle d'Or ${ }^{52}$. Se contienen allí exac-

46 Archivo Capitular de la catedral de Santiago de Compostela, Actas capitulares de la Catedral de Santiago de Compostela; vol. LXII, fol. 391v (13/II/1798), fol. 397, (13/III/1798).

47 SIEMENS HERNÁNDEZ, 1 y 2, (Madrid, 1980) 294. Del mismo autor y SubIRÁ, I (Las Palmas de Gran Canaria, 1985): 302-304; ÁLVAREZ, 1991: 490 y TORRE TRUJILLO, 1979: 278.

48 Archivo capitular de Santiago de Compostela, Leg. Capilla de Música, ss. XVII-XIX; Carta de José Palomino a Sebastián Siquert, Lisboa, 25/XII/1798.

49 Archivo Capitular de la catedral de Santiago de Compostela, Leg. Capilla de Música. Instrumentistas 1734-1787. Los documentos referidos son de 13/VIII/1792, 22/VII/1790 y 15/IX/1805.

50 Archivo de música de la catedral de Santiago de Compostela, Leg. 90/9. LÓPEZ-CALO, 1992: 298-299, núm. 850.

51 LÓPEZ-CALO, 1992: 273.

52 Archivo de música de la catedral de Santiago de Compostela, Leg. 156/11. Vid. LÓPEZ-CALO, 1993c: 191; núm. 3.162. 
tamente tres sinfonías de Paisiello, dos de ellas en el tono de re mayor ${ }^{53}$ y otra en si bemol mayor ${ }^{54}$, una en fa mayor de Traetta, otra de Pugnani, nuevamente en si bemol mayor y finalmente otra en re mayor de Sacchini.

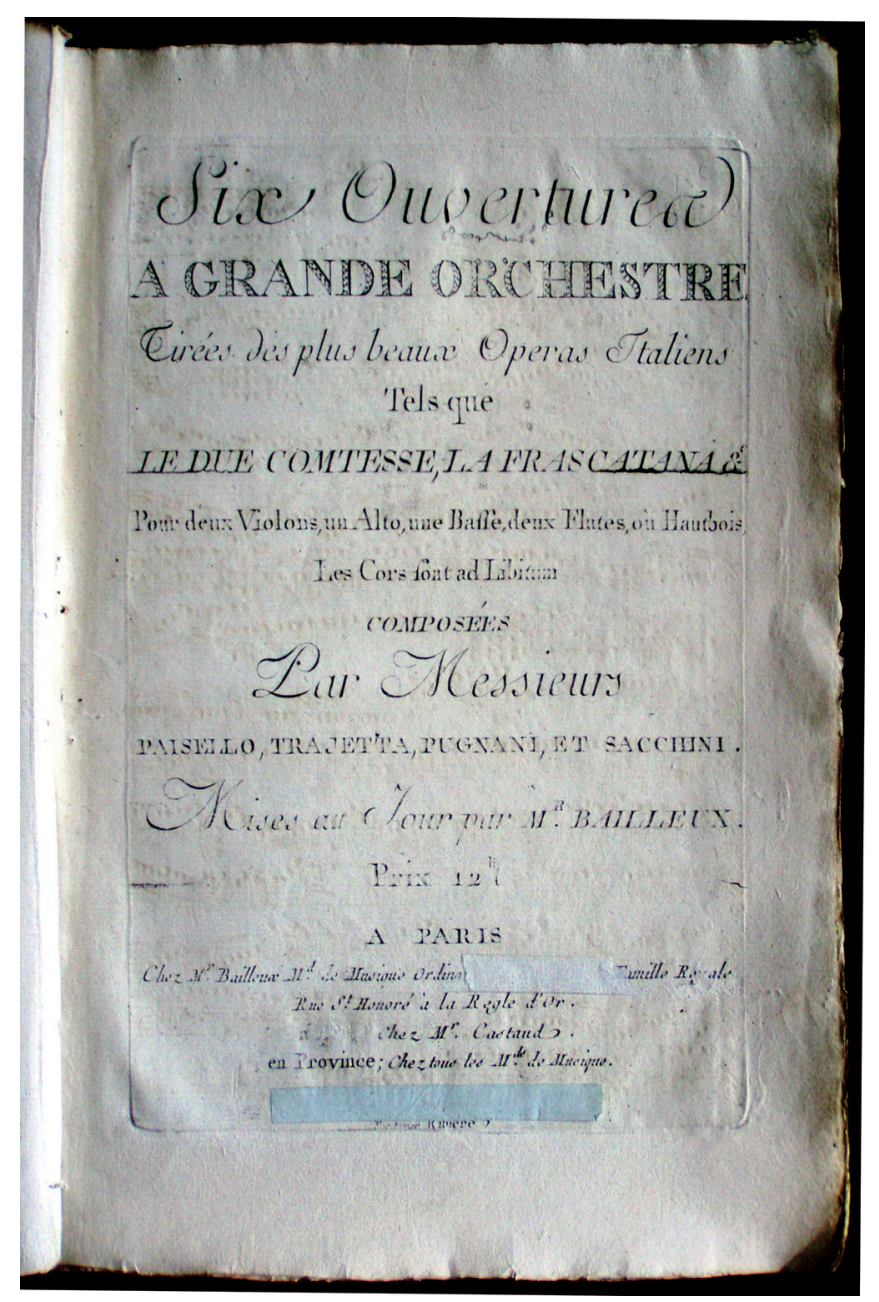

Imagen 4. Portada de las Six Overtures a grande orchestre publicadas por Sieber en París. Archivo de Música de la catedral de Santiago de Compostela. Sin número de catalogación

53 Los dos movimientos iniciales de esta composición son idénticos a los de la sinfonía de Paisiello de la colección manuscrita, variando el último de ellos.

54 Excepcionalmente se trata de una sinfonía escrita en un solo movimiento. 
Esta pequeña colección se abre con la obertura de L’inocente fortunata, ópera de Paisiello y las sinfonías que ocupan los números 3 y 4 las hemos identificado entre las composiciones de este mismo autor, como oberturas de sus óperas La Frascatana y Le due contesse, citadas en el frontispicio de la edición ${ }^{55}$. No hemos identificado el resto de las composiciones, pero señalar que todos los autores lo fueron de ópera y con una importante proyección internacional en sus carreras ${ }^{56}$, muy conocidos en nuestro país, sobre todo en los círculos cortesanos ${ }^{57}$.

Por último, al lado de las sinfonías citadas hay otras obras sueltas de Antoine Baudrón ${ }^{58}$, Françoise Joseph Gossec ${ }^{59}$, Henri Joseph Rigell ${ }^{60}$, Josef Schmit ${ }^{61}$, el Barón de Munchhausen ${ }^{62}$ y el valenciano José Pons ${ }^{63}$ que referenciamos en nota.

\section{SINFONÍAS Y OTRAS COMPOSICIONES INSTRUMENTALES DE FRANZ JOSEPH HAYDN EN EL ARCHIVO DE MÚSICA DE LA CATEDRAL DE SANTIAGO DE COMPOSTELA}

Entre los legajos 157 y 158 del archivo musical de la catedral se conservan un total de doce sinfonías diferentes de Franz Joseph Haydn, tanto manuscritas como en ediciones contemporáneas al autor que constituyen la colección de música instrumental más importante conservada en dicho fondo. Para la mejor comprensión en su conjunto de este grupo de obras tan representativo del estilo sinfónico de su autor, las agruparemos en tres apartados ${ }^{64}$. El primero de ellos está compuesto por dos Simphonies periodiques a plusieur instruments, según señalan sus portadas, en la magnífica edición parisina de Jean Georges Sieber aparecida entre 1782 y $1792^{65}$. Ambas tienen, no obstante, diferente portada; la primera dice: Simphonies periodique a plusieur instruments, composeés par Joseph Haydn, está en si bemol mayor y lleva apuntado a mano en la partichela del violín primero el número 5. Su orquestación es a dos violines, viola, dos oboes, dos trompas y bajo y se trata, en la numeración de Hoboken, de la sinfonía número 71, compuesta por Haydn hacia 1779-80.

La siguiente sinfonía editada en París por Sieber viene titulada de modo diferente a la anterior: Simphonie periodique a plusieur instruments, composeés par Joseph Haydn executé a la Loge Olympi-

55 ROBINSON, 1990: núms. 1.35, 1.43 y 1.50.

56 DEVRIÈS Y LESURE, 1979: 19-20. Vid. también HOPKINSON, 1979: 5.

57 SALAZAR, 1972: 130-132; SUBIRÁ, 9, (Las Palmas de Gran Canaria, 1963): 452-453.

58 LÓPEZ-CALO, 1993c: 187; núm. 3.148, Leg. 154/14; LAURIENCE, 1923: 310 y BROOK, 1962, II: 64-65.

59 Archivo de música de la catedral de Santiago de Compostela, Leg. 156/11; LÓPEZ-CALO, 1993c: 191; núm. 3.162.

60 Archivo de música de la catedral de Santiago de Compostela, Leg. 156/11; LÓPEZ-CALO, 1993c: 191, 199 ; núm. 3.162. BROOK, II, 1962: 362; DEVRIES Y LESURE: 1979, I: 19; HOPKINSON: 1979: 5.

61 Archivo de música de la catedral de Santiago de Compostela, Leg. 159/15; LÓPEZ-CALO: 1993c: 200; núm. 3.201.

62 Archivo de música de la catedral de Santiago de Compostela, Leg. 158/12; LÓPEZ-CALO: 1993c: 198; núm. 3.196.

63 RODRÍGUEZ I BENEITO, 2004; TORRENS I VILAR, 2000: 186-187; LÓPEZ-CALO, 1993A: 78-80; núms. 3.0093.011.

64 HOBOKEN, 1957; BRYANT y CHAPMAN, 1982; BROWN LXIII (Oxford, 1976): 374-394; ROBBINS LANDON, 1975; WYN JONES, 1988: 89-93, 147-156, 215-225 y 254-271; TRUSCOTT, 1983: 17-84.

65 DEVRIÉS: LV, 1 (París, 1959): 20-21. 
$q u e^{66}$ et au Concert Spirituel. En las respectivas partichelas se indica como número 26. Está escrita para los mismos instrumentos que la obra anterior pero con el añadido de dos y su fecha de publicación esta comprendida entre los mismos años que la anterior. En la numeración de Hoboken se corresponde con la sinfonía 84, número 3 de las Sinfonías de París y fue compuesta en el año $1786^{67}$.
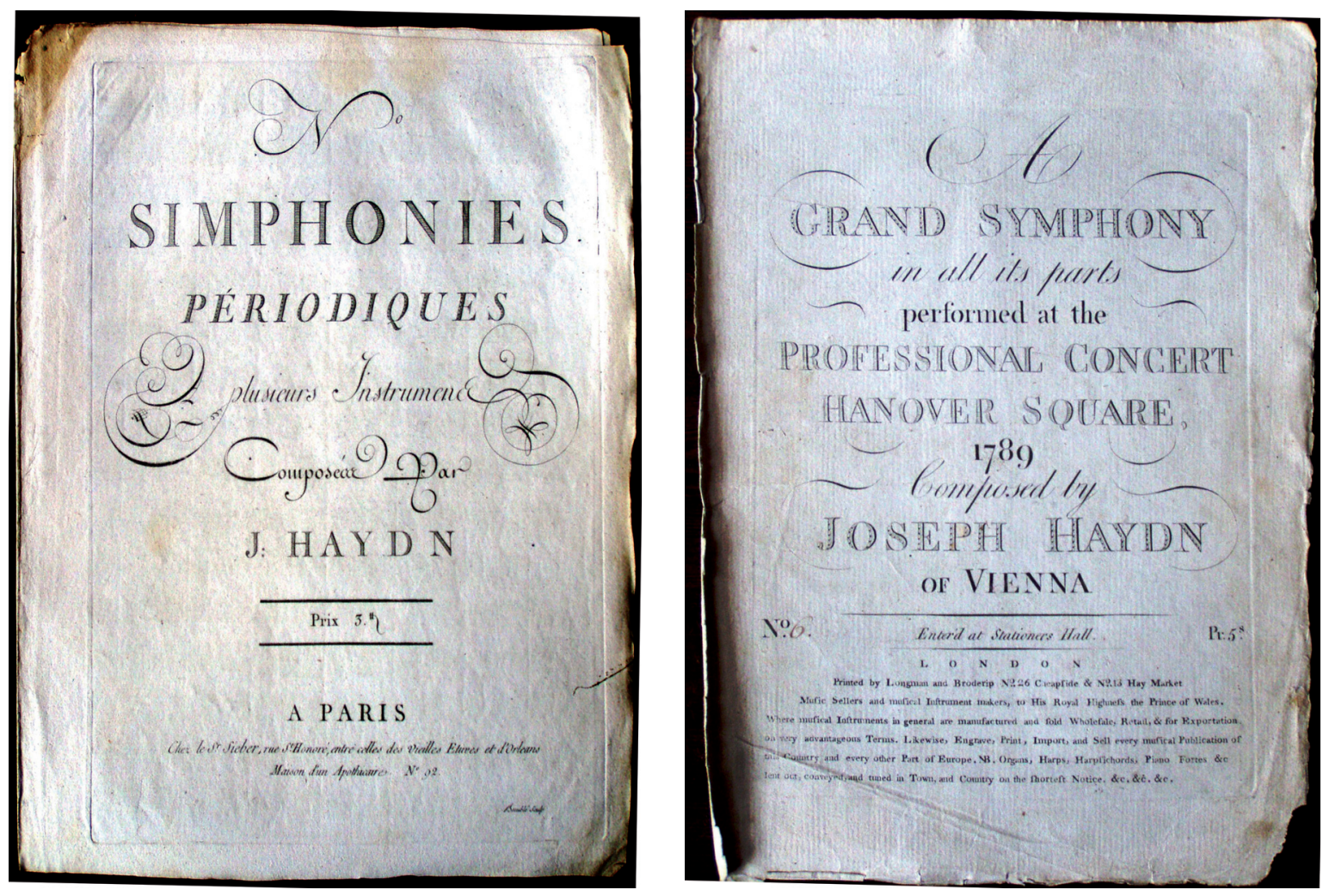

Imágenes 5 y 6. F. J. Haydn: Simphonies periodiques a plusieur instruments. Edición G. Sieber, París. Portada de la Grand symphony in all its parts performed at the Professional Concerts Hannover Square, 1789, composed by Joseph Haydn of Vienna, editada en Londres por Longman \& Broderip. Archivo de música de la catedral de Santiago de Compostela. Sin número de catalogación.

66 QUOY-BODYN, 70 (París, 1984): 95-107.

67 HOBOKEN: 1957, I: 144-145. 
El segundo gran grupo de sinfonías de Haydn conservadas en la catedral compostelana, está integrado por cinco composiciones diferentes, en magnífica edición londinenese de Longman \& Broderip ${ }^{68}$ y que se hallan distribuidas entre los legajos 157 y 158 del archivo de música. Entre ellas, tres sinfonías forman una misma colección correspondiente con la serie editada por el impresor inglés donde se recogen las sinfonías interpretadas en Londres en 1789 durante el primer viaje del maestro al Reino Unido ${ }^{69}$. La portada es única para las tres obras: Grand symphony in all its parts performed at the Professional Concerts Hannover Square, 1789, composed by Joseph Haydn of Vienna.

Dos de ellas se hallan en el legajo 157, llevando la primera añadido a mano sobre la partichela del violín primero $N^{o} 5, O p .51$ y esté en el tono de mi bemol mayor. Además, todas las partichelas llevan añadido el nombre de su instrumento y tonalidad a mano, con grafía que parece la de Melchor López y que en todo caso es síntoma de su uso. Se trata en concreto de la sinfonía número 84, a la que acabamos de referirnos hace un momento por existir en el archivo otra edición de la misma composición, en este caso francesa y algo anterior, de Sieber. La segunda sinfonía de este grupo viene señalada en las partichelas al lado del nombre del instrumento, como núm. 1 y en la portada de la edición como núm. 6. Está en si bemol mayor y es para la misma combinación instrumental que la anterior. En concreto se trata de la sinfonía número 85 que hace el número cuatro de la serie parisina. Fue compuesta hacia 1785-86 y es conocida con el sobrenombre de La Reine.

Otra sinfonía de Haydn, situada al comienzo del legajo 158, pero con igual portada que las anteriores, lleva apuntado a mano, núm 3, Op. 51. La instrumentación incluye clarines y falta entre las partichelas la parte de los timbales que figuran en la instrumentación original. Las partes llevan apuntado el nombre de los instrumentos por otra mano diferente que en los casos anteriores con una escritura que parece ya posterior al magisterio de Melchor López, lo que apunta, en el sentido que señalaba Tafall, hacia su vigencia como repertorio en el siglo XIX. Se trata en concreto de la sinfonía número 82, que es la obra que inicia las sinfonías de París, compuesta en 1786 y conocida con el sobrenombre de L'Ours.

Dos sinfonías más de Haydn editadas por Longman \& Broderip y conservadas en el Archivo tienen portada diferente de las anteriores: Grand symphony in all its parts as performed at Mr. Salomon ` Concert Hannover Square, composed by Joseph Haydn. La primera está en el legajo 157, al lado de las serie publicada por Longmann en 1789. Su tono es el de sol mayor y viene numerada en las partichelas como sinfonía octava. Incluye dos violines, alto, flauta, dos oboes, dos clarines, dos trompas, violonchelo, dos fagotes, contrabajo y timbales. Esta composición presenta la particularidad de que sobre la mayor parte de sus partichelas, parece que Melchor López apuntó: $\operatorname{Sinf} .7^{a}$. La hemos identificado con la sinfonía número 92, Oxford, escrita en 1788.

Con igual portada que esta última obra, y fuera de catálogo, existe otra sinfonía más en el legajo 158, escrita en do mayor que se corresponde con la número 90 del catálogo de Hoboken, compuesta en este caso en 1788 .

68 RADICE, XLIV, 2, (Cambridge, 1983): 90; HUMPRIES y SMITH, 1954: 216.

69 ROSCOE, 49, 3 (Oxford, 1968): 203-204 y SCHROEDER, 1990. 

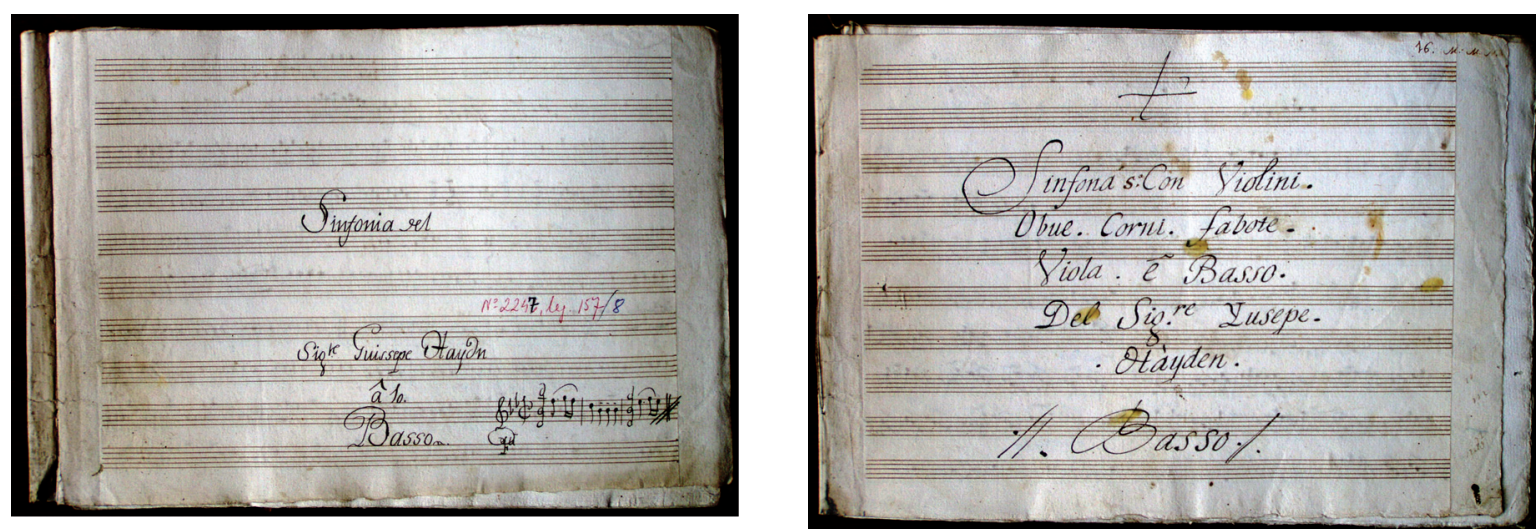

Imágenes 7 y 8. Portada de las partes de basso de dos de las sinfonías de F. J. Haydn (Hob. 53 y Hob. 67) que se conservan manuscritas en el Archivo musical de la Catedral de Santiago de Compostela. Obsérvese como en la esquina superior de una de ellas se encuentra apuntado el tiempo aproximado de su duración, aspecto este usual en las partituras del maestro y en la segunda el íncipit musical

El tercer y último grupo de sinfonías de Haydn conservadas en el archivo de música de la catedral compostelana, lo integran seis obras diferentes de las anteriores conservadas en partichelas manuscritas, dentro del legajo 157 y que no figuran en el catálogo de López-Calo. En cada caso, la hoja que sirve de guarda a sus partichelas lleva cuidadosamente copiado a modo de íncipit los primeros compases del primer movimiento de la parte de violín primero sin dua para facilitar su identificación y elección por el encargado de la música instrumental de la capilla. La sinfonía que abre el grupo lleva la indicación de $1^{a}$ a 10 y está en si bemol mayor. Sus partichelas son, dos violines, viola, flauta, dos oboes, dos trompas y bajo y se trata de la sinfonía 77, compuesta en el año 1782. La segunda viene indicada como Sinfonía II a 8, de Haidn; su orgánico se corresponde con el de la anterior y es la sinfonía 52, compuesta por Haydn hacia 1773. La tercera, se indica como Sinfonía a 10, a lo que se añadió $4^{a}$. El autor está indicado como Giussepe Haydn. Se trata de la sinfonía número 53, conocida como L'Imperiale y compuesta por Haydn hacia 1775. La cuarta y última de este primer apartado de sinfonías manuscritas, es una Sinfonía $5^{a}$ con violini, obue, corni, fabote, viola e basso del Sre. Yusepe Hayden.. Se trata de la sinfonía número 67, compuesta hacia 1778. Las restantes sinfonías manuscritas de este grupo de composiciones, son las dos a 8 del $S^{\text {gre. }}$ Haydn y no muestran ningún tipo de numeración en su portada. La primera la hemos identificado como la sinfonía número 54, escrita en 1774 y la siguiente como la sinfonía número 63, conocida como La Roxolane, escrita por Haydn hacia 1777. Todas las obras que integran este grupo de partituras están copiadas con gran pulcritud, no descartando que fuese el propio Melchor López su copista. Llevan además, apuntado en alguna de sus partichelas (bajo, violín primero, según los casos), la duración de su interpretación en minutos y segundos, un hecho que sirve para hacernos una idea de los tempi empleados en su interpretación y que seguramente esté también relacionado con la funcionalidad de estas composiciones, dentro del espacio temporal marcado por las funciones litúrgicas. Este hecho nos lleva además a 
atribuir con mayor firmeza las copias al maestro Melchor López o por lo menos a su círculo más cercano, habiendo sido música que se interpretó bajo su magisterio, pues él mismo también apuntaba cuidadosamente al final de todas y cada una de las partituras, lo que debía durar cada obra.

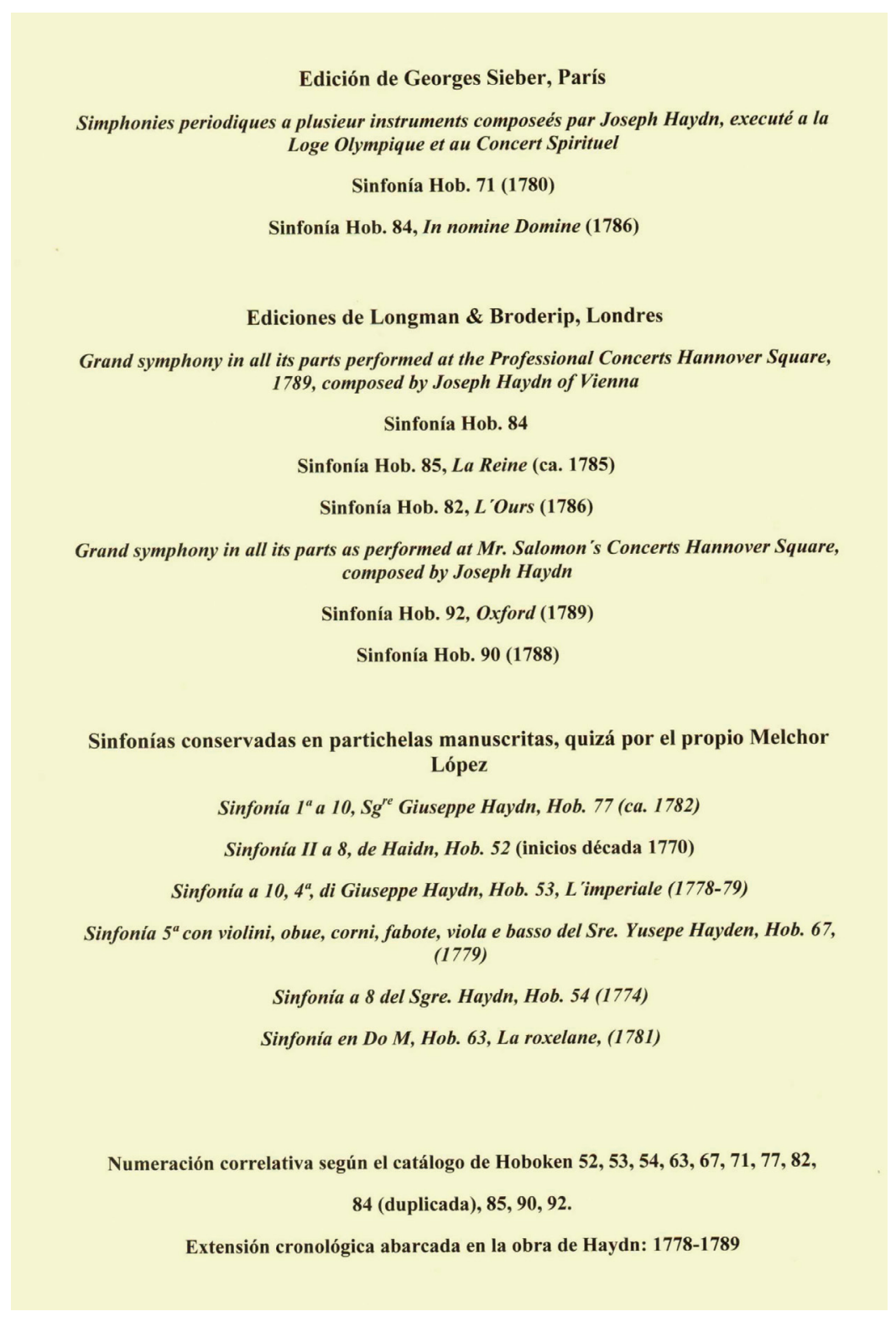

Imagen 7. Distribución tipológica de las sinfonías de F. J. Haydn del Archivo de Música de la catedral de Santiago de Compostela 
Además de las sinfonías y conciertos que se interpretaban dentro de las siestas en la catedral de Santiago, Tafall habla en su Discurso de que durante las festividades del Corpus se tocaban también cuartetos clásicos. Igualmente, el violinista de la capilla Sebastián Siquert, en el documento ya visto por el que solicitaba la compra de obras musicales al Cabildo para la capilla y para su propio estudio, pedía una serie de cuartetos de cuerda de autores como Viotti y Pleyel. Pero a pesar de la evidencia que suponen ambos testimonios, no ha subsistido ninguna partitura de este género en el archivo a excepción de dos fragmentos manuscritos sueltos, tomados de la op. 20 que Haydn publicó en 1771 y que supuso un verdadero cambio en el género así como la apertura de nuevos caminos en la escritura cuartetística ${ }^{70}$. El primero de ellos es la Fuga a 4 soggetti $^{71}$ (Allegro) que cierra el segundo de los cuartetos de la colección ${ }^{72}$ y que parece tratarse de una partitura, posiblemente de procedencia italiana o copiada por un copista de aquel país en el último cuarto del siglo XVIII. El otro fragmento, fuera de catálogo, se encuentra en el legajo 157, envolviendo las partes de la primera de las sinfonías de Haydn allí guardadas ${ }^{73}$ y nos transmite otro pasaje tomado de un cuarteto de cuerda de la misma op. 20, concretamente el Affettuoso e sostenuto, tercero de los movimientos del cuarteto que abre la colección ${ }^{74}$. Como en el caso anterior nos ha llegado en partitura manuscrita, aunque no parece ya de procedencia italiana; más bien debió de ser copiado en Santiago a finales del siglo XVIII o principios del XIX por un copista o músico de la catedral y para su utilización por la capilla.

\section{CONCLUSIONES}

- Siguiendo la teoría de Heartz que expusimos en la introducción, Melchor López es, como lo son L. Boccherini o G. Brunetti un apóstol del Estilo galante en España, pero en otro ámbito diferente al de la música instrumental: el de la música religiosa. No podemos por tanto afirmar que en este aspecto existiese en España un movimiento estético similar al del clasicismo vienés de Haydn y Mozart, aunque si se recepcionase su influencia y en especial la del estilo del primero.

- Durante el magisterio de capilla de Melchor López, la catedral de Santiago contó para su servicio con un conjunto de cantores e instrumentistas que convirtieron a este centro en una de las principales capillas de música del Reino de España.

- Desde su formación y a lo largo de su magisterio compostelano, Melchor López recibió y desarrolló la influencia de la música de Haydn, siendo sus composiciones una muestra evidente de ello y situándolo entre los compositores de música religiosa hispanos más cercanos a la obra del maestro vienés.

70 WIER, 1973: 7, 26-28; HUGES, 1985: 34-35; KONOLD, 1983: 31-39 y WEBSTER, XXVII, 2 (California, 1974): 228-229.

71 Archivo de música de la catedral de Santiago de Compostela, Leg. 51/10; LÓPEZ-CALO: 1993c: 194, núm. 3.179. ALÉN, 1995: 37; MARÍN, 2009: 91

72 HOBOKEN, 1957: 338.

73 Archivo de música de la catedral de Santiago de Compostela, Leg. 157/8.

74 HOBOKEN, 1957: 338. 
- El ideal sonoro que en todo momento intentó plasmar Melchor López en sus composiciones, se corresponde con el de un conjunto sinfónico formado por la cuerda -violines primeros y segundos, violas y bajos-, una pareja de oboes y una pareja de trompas como elementos estables, a los que se unían ocasionalmente flautas y bajones o fagotes.

- Esta plantilla permitió al maestro abordar un repertorio en el que la orquesta es tratada con preciosismo y comparte un indudable protagonismo al lado de la voz. La existencia de este tipo de orquesta sinfónica posibilitó igualmente una profunda transformación en el repertorio instrumental que se interpretaba dentro de la catedral, tanto en las siestas como en las misas y vísperas.

- El fenómeno más relevante a este respecto es, sin duda, la recepción de las sinfonías de F. J. Haydn, quedando importantes testimonios de ello entre los fondos del archivo musical catedralicio.

- La renovación del repertorio instrumental se realizó tanto por el interés indudable del maestro de capilla en su modernización, como por el de los instrumentistas de la capilla, de manera especial, el "concertino" de la orquesta que además de ejercer como solista cuando se le requería en sonatas o conciertos, era también encargado de proveerse de partituras instrumentales y dirigir las academias músicas pertinentes para su interpretación.

- En el caso de Santiago, la ciudad de Lisboa, por medio del compositor y violinista madrileño allí afincado, José Palomino, era el centro que surtía de música instrumental a la catedral.

- La ubicación de esta música en las funciones catedralicias era fundamentalmente en tres momentos: dentro de la misa, tocando diferentes movimientos adecuados a los diversos momentos de la misma (Un allegro de sinfonía en la entrada, un movimiento lento de de sinfonía o de concierto -con solista- en el ofertorio, etc.), en las Vísperas solemnes, a modo de sonata da chiesa antes del canto del Magníficat y en las siestas que se celebraban durante el octavario del Corpus y que Tafall testimonia.

- Respecto a cómo era abordada la interpretación de esta música, señalar que las partituras debían sufrir adaptaciones continuas en relación con los músicos con que contaba en cada momento la orquesta de la capilla; así oboes y flautas podían tocar tanto indistintamente, como reforzándose y mezclando por tanto sus timbres. No podemos afirmar esto mismo respecto del clarinete que si aparece en la orquestación de alguna de las composiciones referenciadas, instrumento y sobre el que Melchor López mostró reticencias a que entrase en la capilla ${ }^{75}$. Sobre la viola y aunque este instrumento tiene presencia documental continuada en la capilla a lo largo del período y el maestro López lo utiliza frecuentemente en sus orquestaciones, en su refuerzo o sustitución es muy probable que se realizase una adaptación de su voz sobre el violín, originándose así un violín tercero como se sucede en otras catedrales y era además práctica

75 No siendo reseñado este dato de importancia en el cuerpo del artículo, incluimos aquí la opinión manifiestamente contraria a la inclusión de los clarinetes en la capilla, expresada por Melchor López en fecha tan tardía como 1818, a raíz de un informe al Cabildo sobre la posible necesidad que tenía la capilla de flautas y clarinetes: (...) Por lo que respecta al clarinete, no habiendo, como no hay en esta capilla, profesor alguno de este instrumento, su falta no se echa de menos, pues de haber uno solo, particularmente en los instrumentos de viento, resultaría, en parte, incompleta la armonía. Últimamente debo manifestar a Vuestra Señoría Ilustrísima que estando trabajadas todas las obras que hay en esta Iglesia determinadamente para el oboe, al sustituir éste por aquel, resultaría un efecto muy inferior al que producen siendo ejecutadas por los primitivos instrumentos para que fueron compuestas. Archivo capitular de la catedral de Santiago de Compostela, Leg. Capilla de Música. Instrumentistas. 1734-1787, 2/III/1819. 
también usual en el barroco, como lo era también que la viola -sin parte escrita- doblase al bajo en su octava aguda para proporcionar mayor equilibrio al conjunto orquestal. Respecto a los bajos de la cuerda, durante algún tiempo debieron subsistir los antiguos violones al lado de los más modernos violonchelos y contrabajos. Era además muy común que en su refuerzo se utilizase un bajón o un fagot, práctica muy común en el barroco y que se encuentra también descrita en diferentes tratados de la época. Estos instrumentos siempre fueron además numerosos en la capilla de la catedral, por actuar acompañando tanto en el canto llano como en el canto de órgano.

\section{BIBLIOGRAFÍA}

ALÉN, M. Pilar, La capilla de música de la Catedral de Santiago en el tránsito del Barroco al Clasicismo, Universidad de Santiago de Compostela, 1986. (Tesis de licenciatura inédita).

ALÉN, M. Pilar, "Músicos italianos en la Catedral de Santiago durante el magisterio de Melchor López", José LÓPEZ-CALO (coord.), Iubilatio. Homenaje de la Facultad de Geografía e Historia a Don Manuel Lucas Álvarez y don Ángel Rodríguez González, Santiago de Compostela, Servicio de Publicaciones e Intercambio Científico de la Universidad: 751-752.

ALÉn, M. Pilar (1991), "Datos para una historia social de la música, La Guerra de la Independencia y su incidencia en la capilla de música de Santiago", Revista de Musicología, XIV, (Madrid, 1991), 1-2, p. 501-510.

ALÉN, M. Pilar, "El Cabildo de Santiago ante dos alternativas, ¿Músicos italianizados o músicos italianos?”, Nassarre, IX, 1, (Zaragoza, 1993): 9-32.

ALÉN, M. Pilar, La capilla de música de la catedral de Santiago de Compostela: renovación y apogeo de una etapa privilegiada (1770-1808), Sada, Ediciós Do Castro, 1994.

ALÉN, M. Pilar, Obras para órgano de Don Melchor López (1759-1822), Santiago de Compostela, Consorcio de Santiago, 2011.

ÁLVAREZ, Rosario, "Prospección en los archivos religiosos tinerfeños del siglo XIX", Actas del III Congreso Nacional de la Sociedad Española de Musicología, la Música en la España del Siglo XIX, Madrid. Sociedad Española de Musicología: 489-496.

AYMES, Jean Renè, La Guerra de la Independencia en España, Madrid, Siglo XXI, 1974.

BAGÜÉS, Jon, Catálogo del antiguo archivo musical del Santuario de Aránzazu, San Sebastián, Caja de Ahorros Provincial de Guipúzcoa, San Sebastián, 1979.

BENTON, Rita, Ignace Pleyel, A thematic catalogue of his compositions, Nueva York, Pendragon Press, 1977. BRYANT, Stephen, CHAPMAN, Gary W, A melodic index to Haydn's instrumental music, a thematic locator for Anthony van Hoboken's “Thematisch-bibliographische wewkverzeishnis”, Nueva York, Pendragon Press, 1982.

BROOK, Barry S, La symphonie française dans la seconde moitié du XVIIIe siècle, II, París, Publicatión de l'Institut de Musicologie de l’Université de París, 1962. 
BROWN, Peter (1976), “Critical years for Haydn's Instrumental music, 1787-90”, Music Quarterly, Oxford, LXIII, 3 (Oxford, 1976): 374-394.

CAPDEPÓN VERDÚ, Paulino, "Música de tecla en la España del siglo XVIII, Domenico Scarlatti y el Padre Antonio Soler", Cuadernos de Estudios del Siglo XVIII, 21, (Oviedo, 2011): 7-34.

CARRERAS, Juan José, La música en las Catedrales en el siglo XVIII. F. J. García "El Españoleto" (1730-1809). Zaragoza. Institución Fernando el Católico, 1983.

CASARES RODICIO, Emilio, "La música en la Catedral de León, Maestros del siglo XVIII y catálogo musical”, Archivos Leoneses, 67 (León, 1980): 7-87.

DEVRIÉS, Anik, "Les éditions musicales Sieber", Revue de Musicologie, LV, 1 (París, 1959): 20-46.

DEVRIÉS, Anik, LESURE, François: Dictionnaire des éditeurs de musique français, Ginebra, Éditions Minkoff, 1979.

DOENBERG, E (1963), “Adalbert Gyrowetz”, Music and Letters, (Oxford, 1963), XLIV: 21-30.

ESLAVA, Hilarión, Breve Memoria Histórica de la Música Religiosa en España. Madrid, Imprenta de Luis Beltrán, 1860.

EZQUERRO ESTEBAN, Antonio, Música instrumental en las Catedrales españolas en la época ilustrada (conciertos, versos y sonatas, para chirimía, oboe, flauta y bajón -con violines y/u órgano-, de la Seo y El Pilar de Zaragoza). Barcelona. CSIC, 2004.

GARBAYO MONTABES, F. Javier, "La crisis de la capilla de música de la Catedral de Santiago durante los últimos años del magisterio de Melchor López (1817-1822)”, Camilo Fernández Cortizo, Domingo L. González Lopo Enrique Martínez Rodríguez (coords.), Universitas. Estudios en Homenaje al Dr. D. Antonio Eiras Roel, Santiago de Compostela, Servicio de Publicaciones e Intercambio Científico de la Universidad. 2002, II: 217-234.

GARBAYO MONTABES, F. Javier, "Instrumentos musicales de la capilla de la Catedral de Santiago de Compostela (1757-1718)”, M. Cármen Folgar dela Calle, Ana E. Goy Díaz y José Manuel López Vázquez (eds.), Memoria Artis. Studia in memoriam M. Dolores Vila Jato, Santiago de Compostela, Xunta de Galicia, 2003, vol. II: 293-304.

GARBAYO MONTABES, F. Javier, "La viola en el ámbito eclesiástico hispano, La orquesta de la capilla de música de la Catedral de Santiago de Compostela y el uso de dos violas en la música de Melchor López (1783-1822)", Anuario Musical, 62, (Barcelona 2007): 229-256.

GONZÁLEZ VALLE, José Vicente, Siete palabras de Cristo en la Cruz, Estudio y edición de, Barcelona, CSIC- Institució Milá i Fontanals.

HEARTZ, Daniel, Music in European Capitals, Nueva York, W. W. Norton \& Company, 2003.

HOBOKEN, Anthony von, Haydn. Tematisch- Bibliographisches Werkverzeichnis, Mainz, I, B. Scholl's Söhne, 1957.

HOPKINSON, Cecil, A dictionary of parisian music publishers, Nueva York, Da Cappo Press, 1979.

HUGES, Rosemary, “Joseph Haydn”, ROBERTSON, Alec, La música de cámara, Taurus Música, Madrid, 1985: 17-59. 
HUMPRIES, Charles y SMITH, William C, Music Publishing in the Brithis Isles from the earliest times to the middle of the nineteenth century, Londres, Casselland Company, 1954.

KONOLD, Rudolph, The String Quartet. From its beginings to Franz Schubert, Nueva York, Heinrischshofen Edition, Nueva York, 1983.

LAURIENCE, Lionell de la, L'école française de violón de Lully à Viotti. Études d'histoire et d'estetique, II, París, Librairie Delagrave, 1923.

LÓPEZ-CALO, José, “Barroco- estilo galante- clasicismo”, Emilio CASARES RODICIO, José LÓPEZ-

CALO e Ismael FERNÁNDEZ DE LA CUESTA (eds.), Actas del Congreso Internacional España en la música de occidente, 2, Madrid, Ministerio de Cultura, 1987, vol. 2: 3-49.

LÓPEZ CALO, José (1988), "La música en Galicia”, Enciclopedia temática de Galicia, Barcelona, Nauta, IV, 1988: 877-931.

LÓPEZ-CALO, José y TRILLO, Joàm, "Melchor López. Misa de Requiem. El Requiem en la música española", Cuadernos de Música en Compostela, I (Santiago de Compostela, Universidad, 1987): 12. LÓPEZ CALO, José y TRILlO, Joàm, Buono Chiodi. Concerto Grosso, Ars Gallaeciae Musicae, 2, Santiago de Compostela, IGAEM, 1992.

LÓPEZ-CALO, José, La música en la Catedral de Santiago, I, A Coruña. Diputación provincial, 1992. LÓPEZ-CALO, José, La música en la Catedral de Santiago, II, A Coruña. Diputación provincial, 1993. LÓPEZ-CALO, José, La música en la Catedral de Santiago, III, A Coruña. Diputación provincial, 1993. LÓPEZ-CALO, José, La música en la Catedral de Santiago, IV, A Coruña, Diputación provincial, 1993. MARÍN, Miguel Ángel (2002), Jaca. Antología musical de la Catedral en el siglo XVIII, Huesca, Diputación Provincial 2002.

MARÍN, Miguel Ángel, “La recepción de Corelli en Madrid (ca. 1680 - ca. 1810)”, G. Barnett (ed.), Arcangelo Corelli fra mito e realtà storica. Nuove prospettive d'indagine musicologica e interdisciplinare nel 350 anniversario della nascita, Florencia, Leo S. Olschki, 2007: 573-635.

MARÍN, Miguel Ángel, Joseph Haydn y el cuarteto de cuerda., Madrid, Alianza Música, 2009.

MARÍN, Miguel Ángel (2010), La ópera en el templo. Estudios sobre el compositor Francisco Javier García Fájer, Instituto de Estudios Riojanos-Institución Fernando el Católico, Logroño-Zaragoza, 2010.

MARTÍN MORENO, Antonio, “Algunos aspectos del barroco musical español a través de la obra teórica de Francisco Valls (1665?-1747)”, Anuario Musical, 31-32 (Barcelona 1976-1977), 157-194

MARTINEZ CUESTA, Juan y KENYON DE PASCUAL, Beryl, "El infante Don Gabriel, gran aficionado a la música”, Revista de Musicología, XI, 3, (Madrid, 1988): 757-806.

MORENO, Emilio, “Aspectos técnicos del tratado de violín de José Herrando (1756): El violín español en el contexto europeo de mediados del siglo XVIII", Revista de Musicología, XI, 3, (Madrid, 1988): 556-584.

NUNAMAKER, Norman K, The virtuoso violin concerto before Paganini, The concertos of Lolli, Giornovichi, and Woldemar, Indiana, Universidad, 1968.

PÉREZ BERNÁ, Juan, “La sinfonía concertante de ¿Buono Chiodi?”, Revista de Musicología, XXI, 2 , (Madrid): 553-572. 
PAVIA I SIMÓ, Josep, Valls. Mapa Armónico Universal. 1742, Barcelona, CSIC, 2002.

QUOY-BODYN, Jean Luc, “L’orchestre de la Société Olympique en 1786”, Revue de Musicologie, 70, (París, 1984): 95-107.

RADICE, Mark A., "Haydn and his publishers. A brief survey of the composer's publishing activities", The Music Review, XLIV, 2, (Cambridge, 1983): 87-94.

RODRÍGUEZ i BENEITO, Ramón, El compositor José Pons i el llenguaje musical per a la Litúrgia de l'ordinarium, "Misa a 4 y a 8 con violines y trompas sobre la antífona Ecce Sacerdos Magnus (1786), Valencia, Universitat Politècnica, , 2004

RONSEN, Charles, The Classical Style, Haydn, Mozart and Beethoven, Nueva York, W. W. Norton \& Company. 1971. Este estudio fue revisado y reeditado por la misma casa en 1997. Edición española, El estilo clásico, Haydn, Mozart, Beethoven, Barcelona, Alianza Editorial, 1986.

ROSCOE, Christopher, "Haydn and London in the 1780's", Music and Letters, , 49, 3, (Oxford, 1968): 203-212.

SALAZAR, Adolfo, La música de España. Desde el siglo XVI a Manuel de Falla, Madrid, Espasa-Calpe, 1972.

SHADKO, Jacqueline, "Francisco Javier Moreno. Life and work", Barry S. BROOK, The symphony, Nueva York y Londres, Garland Publishing, F, IV, 1983: xiii-xiv.

SIEMENS HERNÁNDEZ, Lothar, "José Palomino y su plan de reforma para el mejoramiento de la capilla de música de la Catedral de Canarias (1809)", Revista de Musicología, III, 1 y 2, (Madrid, 1980): 293-305.

SIEMENS HERNÁNDEZ, Lothar, y SUBIRÁ, José, "Música y músicos canarios”, Anuario de Estudios Atlánticos, I, (Las Palmas de Gran Canaria, 1985) pp. 302-304.

SIEMENS HERNÁNDEZ, Lothar, "Los violinistas compositores en la corte española durante el período central del siglo XVIII”, Revista de Musicología, XI, 3, (Madrid, 1988): 657-766.

SCHRÖDER, David P, Haydn and The Enlightenment, The late symphonies and their audience, Oxford, The Clarendon Press, 1990.

SUBIRÁ, José, "El filarmónico D. Tomás de Iriarte”, Anuario de Estudios Atlánticos, 9, (Las Palmas de Gran Canaria, 1963): 441-464.

SUBIRÁ, José, "La música de cámara palatina en el siglo XVIII y principios del XIX”, Boletín de Estudios Madrileños, XII (Madrid, 1971): 25-42.

TAFALL ABAD, Santiago, "La capilla de música de la Catedral de Santiago de Compostela. Notas Históricas”, Boletín de la Real Academia Gallega, XXVI, 131, (La Coruña, Real Academia Gallega, 1931): passim.

TORRENS I VILAR, Joseph María, "La sinfonía en Cataluña (1760-1808)", Juan J. CARRERAS y Malcolm Boyd, La música en España en el siglo XVIII, Cambridge University Press, 2000. 183-200.

TORRE TRUJILLO, Lola de la, "La capilla de música de la Catedral de Las Palmas", Agustín MILLARES TORRES, Historia general de las Islas Canarias, Las Palmas de Gran Canaria, EDIRCA, 1979, vol. IV: 270-279. 
TRILLO, Joàm, “Grandeza y decadencia de la capilla de música”, Ritmo, LIII, 527, (Madrid, 1984): 20-24. TRILLO, Joàm (ed.), Melchor López. Misa Solemne Unus Deus. A 8 v. e orquestra (1798), Ars Gallaecia Musicae, 10, Santiago de Compostela, IGAEM, 1996.

TRILLO, Joàm, “A Misa Unus Deus de Melchor López”, Música Clásica Galega, 4, (Santiago de Compostela. 2003): 10 .

TRUSCOTT, Harold, “Joseph Haydn y el nacimiento de la sinfonía clásica”, SIMPSON, Robert, La sinfonía (I). De Haydn a Dvorak, Madrid, Taurus Música, 1983: 17-84.

VILLANUEVA, Carlos, "Grandeza y decadencia de la capilla de música”, José María DÍAZ FERNÁNDEZ y Ramón YZQUIERDO PEIRÓ, 800 aniversario Catedral de Santiago, Santiago de Compostela, Consorcio de Santiago, 2011.

VIGO TRASANCOS, Alfredo, “Galicia y la arquitectura neoclásica (1750-1834). La vuelta al orden”, Carlos del PULGAR SABÍN (ed.), José Manuel HIDALGO CUÑARRO (coord.), Arte e Cultura. Galicia e Norte de Portugal. Arquitectura, II, Vigo, Nova Galicia Edicións, 2004.

ROBBINS LANDON, Harold C, Haydn symphonies, Londres, BBC Music Guides, 1975.

ROBBINS LANDON, Harold C. y WYN JONES, David, Haydn, his life and music, Londres, Thames and Hudson, Londres, 1988.

ROBINSON, L, Giovanni Paisiello. A thematic catalogue of his works, Nueva York, Pendragon Press, 1990.

DEVRIÈS, Anik y LESURE, François DeVRIÈs, Dictionnaire des éditeurs de musique français, Ginebra, Éditions Minkoff, 1979.

WEBSTER, James, "Towards a history of viennese chamber music in the early classical period”, Journal of American Musicological Society, XXVII, 2, (UCLA, 1974): 212-247.

WEBSTER, James, “The eigtheenth century as a music-historical period?", Eighteenth-Century Music, 1, 1 (Cambridge, 2004): 47-60.

WHITE, Chapell, G. Battista Viotti (1755-1824). A thematic catalogue of his works, Nueva York, Pendragon Press, 1985.

WIER, Albert E, The chamber music of Haydn and Schubert, Nueva York, Belwin Mills Publishing Corp, Nueva York, 1973.

Recibido: $24 / 08 / 2010$

Aceptado: 21/02/2013 